OPEN ACCESS

Edited by:

Daniela Popa

Transilvania University of Braşov,

Romania

Reviewed by:

Ghulam Abid,

Kinnaird College for Women

University, Pakistan

Suzy Green,

University of East London, United Kingdom

${ }^{*}$ Correspondence:

Yanling Wang

ynufewyl@126.com

Specialty section:

This article was submitted to

Organizational Psychology, a section of the journal

Frontiers in Psychology

Received: 26 January 2021

Accepted: 06 July 2021

Published: 05 August 2021

Citation:

Liu D, Zhang S, Wang Y and

Yan Y (2021) The Antecedents

of Thriving at Work: A Meta-Analytic

Review. Front. Psychol. 12:659072.

doi: 10.3389/fpsyg.2021.659072

\section{The Antecedents of Thriving at Work: A Meta-Analytic Review}

\author{
Danping Liu ${ }^{1,2}$, Siwen Zhang ${ }^{3}$, Yanling Wang ${ }^{4 *}$ and Yufei Yan ${ }^{5}$ \\ ${ }^{1}$ School of Management, Xihua University, Chengdu, China, ${ }^{2}$ Research Institute of International Economics and \\ Management, Xihua University, Chengdu, China, ${ }^{3}$ Darla Moore School of Business, University of South Carolina, Columbia, \\ SC, United States, ${ }^{4}$ Business School, Yunnan University of Finance and Economics, Kunming, China, ${ }^{5}$ School of Business \\ Administration, Southwestern University of Finance and Economics, Chengdu, China
}

In this study, a systematic and comprehensive meta-analysis of the relationship between thriving at work and its antecedents is conducted. The antecedents in terms of the characteristics of unit contextual features, the resources produced at work, agentic work behaviors, and personality traits are illustrated according to the socially embedded model of thriving described by Spreitzer and research. Additionally, we examine possible cultural influence on the relationship between thriving and its antecedents at different levels of individualistic culture. According to 67 independent samples ( $N=28,097$ ), our findings reveal the correlations between thriving at work and the antecedents such as those in the form of unit contextual features, the resources produced at work, agentic work behaviors, and personality traits. Furthermore, we find that individualism moderate the relationships between certain antecedents and thriving at work. Finally, we discuss the theoretical and practical implications of this study as well as the directions for future research.

Keywords: thriving at work, antecedents, unit contextual features, resources produced at work, individual agentic work behaviors, personality traits, national culture

\section{INTRODUCTION}

Being a positive psychological state, thriving at work has attracted increased attention in recent decades. It is defined as "the joint experience of a sense of vitality and learning and is most accurately conceptualized as a continuum-where people are more or less thriving at any point in time-rather than a dichotomous state of either thriving or not" (Porath et al., 2012, p. 250). Thriving is extremely important, because vitality and learning are the two key factors in improving performance and well-being, to talented employees who face intensifying competitions in the workplace (Pfeffer, 2010).

Several scholars and managers have paid attention to thriving at work due to its positive effects. A few studies have shown that thriving at work contributes to the improvement of task performance, job satisfaction, and physical well-being (Spreitzer et al., 2012). Furthermore, Porath et al. (2012) proposed that thriving was a different construct when compared to a positive/negative effect and learning goal orientation, etc., and found this notion, which in turn could better explain these outcomes. Compared with employees who fail to be in the state of thriving, employees who are in the state of thriving at work can continue to acquire growth and self-development, which ultimately promote organizational efficiency and prosperity (Han and Wei, 2013). In addition, employees are more likely to have negative emotions due to an increasing competition in the workplace, which induces many problems such as burnout, the lack of work vitality, and even poor 
health conditions. Therefore, it is always the pursue for managers to keep employees vigorous and efficient at work. In sight of the importance of thriving in the workplace, it is critical to explore the factors that motivate employees' thriving at work.

Many factors, including organizational context, job characteristics, and personal factors, have an impact on employees' thriving at work such as perceived organizational support (Collins, 2014), trust (Carmeli et al., 2009), workplace incivility (Panagiotis et al., 2013), job crafting (Han, 2017), challenge stress (Flinchbaugh et al., 2015), and proactive personality (Albi et al., 2020). Recently, some other constructs have served as important antecedents of employees' thriving at work such as workplace friendship (Chen et al., 2016), taking charge (Xu et al., 2020), and social functioning (Zhang et al., 2020). Despite these profound research findings, some inconsistent conclusions were obtained. For example, Jaiswal and Dhar (2017) found that work experience was one of the important drivers of thriving at work. However, it was confirmed by Zhang R. G. et al. (2018) that individuals with more work experience were lacking in thriving at work. Such a discrepancy probably arises due to the accuracy of statistical results being subjected to the possible measurement and sampling error and the moderating role of some contingent variables. Therefore, a meta-analysis is needed to address this problem by integrating the existing results in empirical studies by controlling both kinds of statistical errors and considering some contextual factors.

By systematically examining the antecedents of the characteristics of individuals and relational resources, the metaanalysis mentioned in Kleine et al. (2019) provided a general research framework according to the socially embedded model of thriving (Spreitzer et al., 2005). Despite being influential, their study excluded some other prominent categories of indicators such as unit contextual features and individual agentic work behaviors. Simultaneously, a greater number of indicators in each category of antecedents are needed to be further explored, thus necessitating a more in-depth exploration and finely grained meta-analytic review of the antecedents that engender thriving.

Furthermore, the impact of culture on the relationship between thriving and its antecedents requires investigation, ensuing the potential variations in the relationships among various indicators and thriving, identified in a previous study, as existing across cultural contexts (Rozkwitalska, 2018). Specifically, according to the socially embedded model of thriving at work (Spreitzer et al., 2005), the personal development of employees depends heavily on dynamic interactions with others, which are assumed to occur in different patterns, in various cultural contexts. However, the effects of these different patterns in different cultures, on various indicators and thriving, are not yet known.

This study contributes to this field in several ways. Firstly, we have extended the research of Kleine et al. (2019) by integrating additional categories of antecedents into the existing research model. We meta-analyzed the relationship between unit contextual features and thriving, such as challenge stressors, hindrance stressors, work control, job crafting, and organizational justice, which is not noted in their study. We also performed a meta-analysis of the relationship between thriving at work and individual agentic work behaviors such as task focus, exploration, and heedful relating. Secondly, to supplement the study by Kleine et al. (2019) on resources and personality traits (antecedents), we conducted a review of several types of resources produced at work, which promote employees' thriving, including types of leadership, positive meaning, and work experience. A further meta-analysis of four additional types of personality traits, including self-efficacy (Geiger, 2013), optimism, openness, and conscientiousness, was also performed. Thirdly, we discuss the differences in the relationships between thriving and its antecedents across employees from different cultures. Specifically, we examine the moderating effects of individualistic culture on the relationship between thriving and its antecedents.

\section{THEORETICAL BACKGROUND AND HYPOTHESES}

\section{Theoretical Backgrounds}

Previous empirical studies have paid close attention to the antecedents of employees' thriving at work. Some studies explored the motivators who enable employees to thrive at work from the perspective of the characteristics of individuals such as psychological capital (Paterson et al., 2014), proactive personality (Albi et al., 2020), and positive affect (Porath et al., 2012). Furthermore, a series of empirical studies have been carried out for studying the impact of organizational context on employees' thriving at work. For instance, the existing research covers leadership style (Russo et al., 2018), managerial coaching (Raza and Ahmed, 2020), fairness perception (Ghulam et al., 2020), etc. Other studies focus on job characteristics, including innovation and feedback (Xie, 2016), decision-making discretion (Liu and Bern-Klug, 2013), challenging stress (Prem et al., 2017), etc. Meanwhile, some researchers explored the effects of some antecedents on employees' thriving at work from the perspective of workplace interpersonal relationship. The existing results show that workplace friendship (Chen et al., 2016), colleague relationship (Xie, 2016; Ehrhardt and Ragins, 2019), workplace incivility (Gkorezis et al., 2013), and knowledge hiding (Jiang et al., 2019) will also affect employees' thriving at work in different ways.

As shown in Table 1, although they were not exhaustive, the major determinants of thriving at work were summarized through an in-depth review of its antecedents. Because a number of fruitful and influential achievements have been made on the topic of employees' thriving at work in these years, it is necessary to systematically review and sort out the scattered research, not only to reflect on its omissions and weaknesses but also to make forward-looking prospects for future research.

In this respect, Spreitzer et al. (2005) and Kleine et al. (2019) systematically summarized these antecedents and proposed different theoretical frameworks for the following researchers to better grasp important findings in this research field.

Specifically, Spreitzer et al. (2005) proposed a socially embedded model of thriving at work, which explained how individual learning and vitality should be integrated into 
TABLE 1 | Summary of the antecedents of thriving at work.

\begin{tabular}{|c|c|}
\hline Antecedents & References \\
\hline Abusive supervision & $\begin{array}{l}\text { Liu (2016), Luo (2016), Zhao et al. (2018), } \\
\text { Usman et al. (2021) }\end{array}$ \\
\hline Authentic leadership & $\begin{array}{l}\text { An (2015), Mortier et al. (2016), Xu et al. (2017), } \\
\text { Shen et al. (2018) }\end{array}$ \\
\hline Autonomy & Gu (2015), Xie (2016), Li (2018) \\
\hline Broad information sharing & Liu and Bern-Klug (2013) \\
\hline Challenge stress & Flinchbaugh et al. (2015), Prem et al. (2017) \\
\hline Conscientiousness & Hennekam (2017) \\
\hline $\begin{array}{l}\text { Decision-making } \\
\text { discretion }\end{array}$ & $\begin{array}{l}\text { Liu and Bern-Klug (2013), Sia and Duari (2018), } \\
\text { Novaes et al. (2020) }\end{array}$ \\
\hline Empowering leadership & Li et al. (2016), Han (2017), Ali et al. (2018) \\
\hline Exploration & Sia and Duari (2018) \\
\hline Fairness perception & Ghulam et al. (2020) \\
\hline Feedback & Lee et al. (2015), Xie (2016) \\
\hline Heedful relating & $\begin{array}{l}\text { Niessen et al. (2012), Ted et al. (2013), Paterson } \\
\text { et al. (2014), Abid et al. (2016), Sia and Duari (2018) }\end{array}$ \\
\hline $\begin{array}{l}\text { High-performance work } \\
\text { system }\end{array}$ & Liu (2017), Zhang et al., (2018) \\
\hline Job crafting & Han (2017), Wang (2018) \\
\hline Job satisfaction & Hennekam (2017), Zhao et al. (2018) \\
\hline Knowledge resources & Niessen et al. (2012) \\
\hline LMX & An (2015), Li (2015), Xu et al. (2017), Zhang (2018) \\
\hline Managerial coaching & Commer et al. (2017), Raza and Ahmed (2020) \\
\hline Negative affect & Porath et al. (2012) \\
\hline Openness & Hennekam (2017), Hildenbrand et al. (2018) \\
\hline Organizational justice & Deng (2016), Bensemmane et al. (2018) \\
\hline $\begin{array}{l}\text { Paradoxical leader } \\
\text { behavior }\end{array}$ & Liu et al. (2019), Yang et al. (2021) \\
\hline $\begin{array}{l}\text { Perceived organizational } \\
\text { support }\end{array}$ & $\begin{array}{l}\text { Collins (2014), Abid et al. (2015), Gao D. (2017), } \\
\text { Shen et al. (2018) }\end{array}$ \\
\hline Positive affect & Porath et al. (2012) \\
\hline Positive meaning & Niessen et al. (2012), Prem et al. (2017) \\
\hline Proactive personality & Jiang (2017), Albi et al. (2020) \\
\hline Prosocial motivation & Ghulam et al. (2018) \\
\hline Psychological safety & $\begin{array}{l}\text { Kark and Carmeli (2010), Xu et al. (2017), } \\
\text { Jiang et al. (2019) }\end{array}$ \\
\hline Psychological capital & $\begin{array}{l}\text { Ted et al. (2013), Paterson et al. (2014), } \\
\text { Chen et al. (2016), Levy (2016), Shen et al. (2018) }\end{array}$ \\
\hline Relational resources & Niessen et al. (2012) \\
\hline Self-efficacy & $\begin{array}{l}\text { Gao D. (2017), Bensemmane et al. (2018), } \\
\text { Zhu et al. (2019) }\end{array}$ \\
\hline Servant leadership & Luo (2016), Walumbwa et al. (2018) \\
\hline Social functioning & Zhang et al. (2020) \\
\hline Supportive climate & Ted et al. (2013), Paterson et al. (2014) \\
\hline Taking charge & Xu et al. (2020) \\
\hline Task focus & $\begin{array}{l}\text { Niessen et al. (2012), Ted et al. (2013), } \\
\text { Paterson et al. (2014), Sia and Duari (2018) }\end{array}$ \\
\hline $\begin{array}{l}\text { Transformational } \\
\text { leadership }\end{array}$ & $\begin{array}{l}\text { Collins (2014), Huang (2017), Niessen et al. (2017), } \\
\text { Dong (2018), Hildenbrand et al. (2018) }\end{array}$ \\
\hline Trust & $\begin{array}{l}\text { Carmeli and Spreitzer (2009), Koçak (2016), } \\
\text { Li (2018), Xu et al. (2020) }\end{array}$ \\
\hline Work control & Li (2018), Wang (2018) \\
\hline Work family enrichment & $\mathrm{Na}$ (2017), Russo et al. (2018) \\
\hline Workplace friendship & Chen et al. (2016) \\
\hline Workplace civility & Ghulam et al. (2018) \\
\hline Workplace incivility & Panagiotis et al. (2013) \\
\hline Workplace violence & Zhao et al. (2018) \\
\hline
\end{tabular}

social systems. They argued that employees thrive through an interaction with others in the workplace, by observation, and by communication with supervisors or colleagues. They also identified the two key predictors of thriving: "The social structural features of the focal work unit context and resources produced at work" (Spreitzer et al., 2005, p. 540). The context of the focal work unit included the social structural features of encouraging a discretion in decision-making, broad information sharing, and a climate of trust and respect. The resources produced at work included a sense of knowledge, positive meaning, positive affective resources, and relational resources. Further, they proposed three agentic work behaviors that predict thriving: task focus, exploration, and heedful relating.

Kleine et al. (2019) meta-analyzed the relationship between antecedents and thriving according to the socially embedded model of Spreitzer et al. (2005), but focused on thriving from the perspective of the characteristics of individuals and the relational resources involved. However, their model excluded the context of the work unit to be focused. Such factors included the social structural features of work demand, feedback, work autonomy, job crafting, and more. Their model also did not consider agentic work behaviors such as exploration and task focus. Furthermore, although they examined the characteristics of individuals such as core self-evaluation and proactive personality, certain personal attributes, such as self-efficacy, were excluded.

Both abovementioned frameworks are essential for us to acknowledge the indicators for employees' thriving and fully encourage the enterprises to use corresponding strategies to motivate the employees to be more thrived. However, through a comparably comprehensive review of existing empirical studies, we find that there still exists some other important antecedents of employees' thriving, which need further attention. Furthermore, we believe it is necessary to combine both the frameworks to figure out all possible antecedents as thoroughly as possible.

Therefore, this research extends the abovementioned basic frameworks by combining the models of Spreitzer et al. (2005) and Kleine et al. (2019) and systematically reviewing the antecedents of thriving. Considering the literary inclusion criteria of meta-analysis and some constructs, which were by Kleine et al. (2019), the study includes a comprehensive review of the effects of the contribution of unit contextual features, the resources produced at work, and the agentic work behaviors to thriving at work. Additionally, several types of personality traits, which were excluded from the previous frameworks, have been meta-analyzed. Meanwhile, this study follows a moderating effect of individualism on the links of antecedents and employees' thriving with great interest, which has gained limited attention by existing studies. Figure 1 shows the research framework employed for this study.

\section{HYPOTHESIS DEVELOPMENT}

\section{Unit Contextual Features}

According to Spreitzer et al. (2005), reducing stressors in the workplace alone is not a sufficient encouragement for employees to thrive. Other workplace factors, such as enabling 


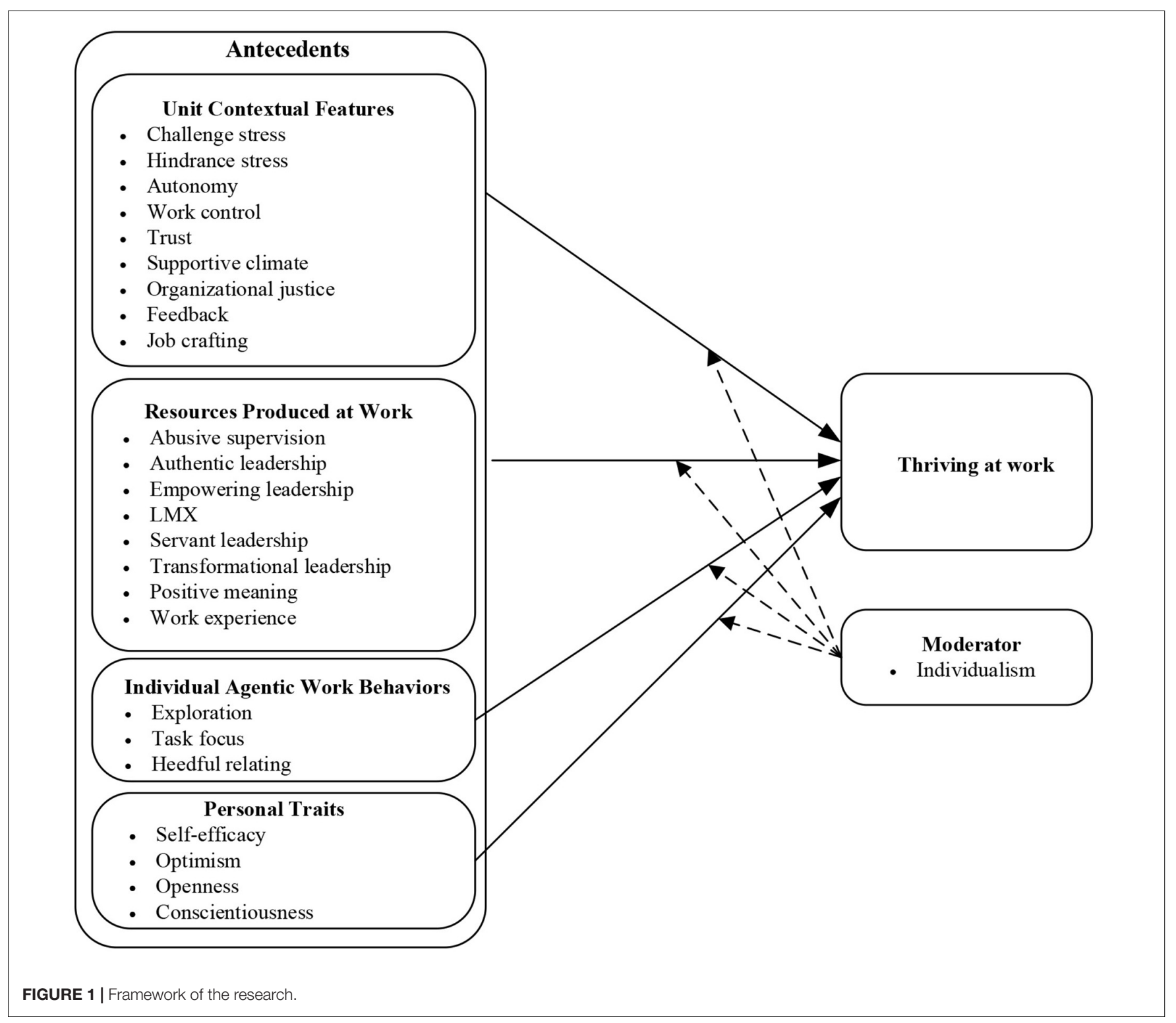

conditions, are also the crucial motivators of employees' thriving. Therefore, unit contextual features are considered as an important indicator of thriving that should not be overlooked when examining its antecedents. Spreitzer et al. (2005) stated that unit contextual features are the characteristics of the individual work environment of an employee and include expectations, work practices, and operating procedures (Spreitzer et al., 2005, p. 541). We also argue that various workplace characteristics, work practices, and procedures may facilitate or impede a climate of information sharing, decision-making discretion, and trust. Therefore, we start with a review of the influences of various contextual characteristics on thriving.

\section{Challenge Stress}

It is a stressor that positively induces personal learning, growth, and accomplishment (LePine et al., 2004). Flinchbaugh et al. (2015) provided a challenge-hindrance framework, which evidenced that challenge stressors have the opposite effect on general stress, mitigate the passive effects of hindrance stressors, improve thriving, and increase employee life satisfaction. Further, their study shows that challenge appraisals indicate the magnitude of challenge stress and motivate employees to handle their daily workload effectively while actively experiencing a sense of learning. Prem et al. (2017) conducted a more detailed, diary study of the divided aspects of thriving, measuring the effects of two challenge stressors (i.e., time pressure and learning demands) in the workplace. On the two aspects of thriving, challenge stressors positively affected learning but had no impact on vitality. Generally speaking, challenge stress, which variably depends on the industry, employee's age, tenure, and the nature of the firm, is positively associated with employee thriving (Huang, 2017). Therefore, we propose the following hypothesis:

H I-1: Challenge stress is positively related to thriving at work. 


\section{Hindrance Stress}

In contrast to challenge stress, hindrance stress represents the pressure to perform mundane and repetitive tasks (LePine et al., 2004). According to Dollard et al. (2013), hindrance stress, measured by hindrance appraisals, is closely related to the feelings of low morale. Thus, it reduces worker satisfaction and undermines thriving (LePine et al., 2004). Additionally, when compared with challenge stress, hindrance stress discourages individual growth and its beneficial consequences as individuals use their limited resources, of time and energy, to cope with meaningless, mundane, and repetitive tasks. Subsequently, individuals perceive thriving as a strain in the workplace (Flinchbaugh et al., 2015). For example, Huang (2017) found that hindrance stress is negatively associated with thriving according to the field and online research including 542 questionnaires in East China. Therefore, we propose the following hypothesis:

$\mathrm{H}$ I-2: Hindrance stress is negatively related to thriving at work.

\section{Autonomy}

It refers to the sense of volition and control that employees experience in improving their work efficiency (Rhoades and Eisenberger, 2002). A high degree of autonomy, along with other components of intrinsic motivation, can contribute toward thriving, including vitality and learning (Geiger, 2013). Mukhaimer (2012) concluded that autonomous motivation positively affects thriving because employees feel better in a flexible work environment. According to Sia and Duari (2018), decision-making authority is critical to work satisfaction and involvement and is a key motivator for employees to thrive. Decision-making authority can enhance employee autonomy and interact with task focus, thereby motivating employees to learn and work harder. Several studies (e.g., van Scheppingen et al., 2015; Li et al., 2016) have revealed a more direct, more detailed relationship between autonomy and vitality, namely, half of thriving, whereby increased vitality stimulates the active involvement of employees, thus encouraging thriving behavior at work. Therefore, given a proper autonomy, employees experience a greater mental motivation and thriving, which effectively increases their desire to work (Gu, 2015; Xie, 2016; Gao F., 2017; $\mathrm{Li}, 2018)$. In light of the aforementioned studies, we propose the following hypothesis:

H I-3: Employee autonomy is positively related to thriving at work.

\section{Work Control}

In terms of work control, employees can manage their own work tasks and plans, granting them greater flexibility and decision-making power (Quick et al., 1990). Cheng et al. (2013) concluded that employees with more control tend to perform better and remain more positive about their work than those with less control. Therefore, the ability to control work with optimistic synergy motivates employees to confidently face the challenges of their work (Cheng et al., 2013). Additionally, strengthening the supervision and control and focusing on comparisons between work goals and outcomes improve vitality and learning processes. Employees are more likely to effectively control the quality of their work when using the quality of outcomes to set appropriate job requirements. With improved work outcomes, employees who are acknowledged for their abilities are motivated to continue working (Li, 2018). By effectively controlling work, employees can gain more resources, such as objective opinions, positive emotional, and behavioral management, which encourage employee thriving. Therefore, we propose the following hypothesis:

H I-4: Work control is positively related to thriving at work.

\section{Trust}

It is defined as a part of interpersonal relationships at work and plays a significant role in predicting the thriving of employees. It is the belief that another party can perform well without being forced to reach the target (Koçak, 2016). Trust can be divided into three aspects: a management team, a supervisor, and colleagues. Trust in a management team is developed when an employee feels supported and shows that he/she relies on the decisions of the organization. The relationship between employees and their supervisors and/or colleagues also emphasizes trust on a smaller scale (Koçak, 2016). High-quality relationships are beneficial in motivating the employees to be more active at work and when interacting with supervisors and colleagues, and ultimately thrive more (Li, 2018). Additionally, employee trust in leaders equips leaders with power and authority for management, and trust in employers ensures that employers are more capable of supervision and learn from colleagues. With the proper guidance of supervisors and colleagues, employees are more willing to thrive in a voluntary manner (Jaiswal and Dhar, 2017). Through collective trust-based interactions, employees enjoy high-quality social bonds and a higher level of thriving at work. Carmeli et al. (2009) explored the relationship between positive work relationships and vitality in an alternative explanatory path. With trust, building high-quality relationships encourages employees to have the confidence to actively express their personal opinions. It also enables employees to respect the requirements of their work. Therefore, we propose the following hypothesis:

H I-5: Trust is positively related to thriving at work.

\section{Supportive Climate}

The workplace environment can positively or negatively affect employees (Paterson et al., 2014). In a supportive and friendly environment, supervisors tend to pay attention to their subordinates and express concern in many aspects, including work performance and individual development. They also tend to provide a variety of resources to help with employee tasks. These behaviors facilitate the work of an employee and encourage them to work agentically, which leads them to thrive (Paterson et al., 2014). Additionally, the social support provided by supervisors and colleagues can be helpful in supporting employees to feel secure in their jobs. In short, under a supportive climate, unconfident or confused employees are motivated by suggestions for improvement, increasing their likelihood of thriving well for a longer period of time (Cheng et al., 2013). Zhu et al. (2019) discovered the positive effect of a supportive environment among 
a particular group of workers, namely, people with disabilities. They also suggested that a climate of team learning can reduce the negative impact of disability and ultimately enhance the thriving of people with disabilities. Therefore, we propose the following hypothesis:

H I-6: A supportive workplace climate is positively related to thriving at work.

\section{Organizational Justice}

It is perceived as the opinion of an employee on workplace equity (Colquitt et al., 2001). Bensemmane et al. (2018) argued that, despite an individual variation, the overall average sense of justice across a team contributes to the collective thriving of team members. Mushtaq et al. (2017) uncovered the mechanisms underlying the influence of justice on employee thriving and suggested that employees with a higher sense of organizational justice show greater confidence in the assessment and reward system of an organization. Given this belief, employees concentrate on their work and pursue performance improvement, which translates to a higher degree of thriving. Working in an organization that emphasizes the improvement of three components of justice, including procedural, interactional, and distributive justice, drives the motivation for employees to thrive (Deng, 2016). Thus, we propose the following hypothesis:

$\mathrm{H} \mathrm{I-7:} \mathrm{Organizational} \mathrm{justice} \mathrm{is} \mathrm{positively} \mathrm{related} \mathrm{to} \mathrm{thriving}$ at work.

\section{Feedback}

It is a way for supervisors to provide information to subordinates according to the outcomes of their work (Maurer et al., 2002). Useful feedback not only provides an incentive for employees to learn new skills and ideas but also potentially transforms the workplace to an open and a transparent system, significantly increasing employee thriving (Xie, 2016). In terms of an integrative model of human growth in the workplace, Gao F. (2017) concluded that supervisory developmental feedback positively affects the basic psychological needs of employees and further influences their thriving. Supervisors use verbal encouragement and express concern to build relationships with their subordinates. This effective interaction strengthens employees' sense of belonging to the organization and guides them on how to improve their work, which ultimately stimulates thriving (Wang et al., 2017). Lee et al. (2015) stated that feedbackseeking behavior in a team feedback environment can also significantly improve the work performance and attitude of employees, leading to increased thriving as employees become clear about their work abilities and responsibilities. Therefore, we propose the following hypothesis:

H I-8: Work feedback is positively related to thriving at work.

\section{Job Crafting}

It refers to the behavior of an employee in modifying and adjusting the content of a job to improve performance; a process that clarifies and confirms their job requirements and their own beliefs (Wrzesniewski and Dutton, 2001). This leads to the conclusion that employees with positive and enthusiastic attitudes toward work ultimately experience thriving (Li, 2015). Employees who craft their jobs strengthen their awareness of their duties and abilities. After proper positioning, they use organizational resources more efficiently and feel motivated to learn on their jobs (Wang, 2018). Additionally, job crafting enables employees to take on challenges, advance their knowledge, and lay the foundation for their personal growth. Through this process, the advantages of concentration and progress at work motivate employees with crafted jobs to thrive at a higher level (Han, 2017). Therefore, we propose the following hypothesis:

H I-9: Job crafting is positively related to thriving at work.

\section{Resources Produced at Work}

There are other factors, in addition to the influence of the different unit contextual features on employee learning and vitality, which influence employee thriving, including the resources produced at work. In the socially embedded model of thriving of Spreitzer et al.'s (2005), various types of resources can facilitate employee's thriving, such as knowledge resources, a positive meaning, and relational resources. In this section, according to the existing empirical research, we perform a metaanalysis to examine the effects of various types on leadership, defined as a type of relational resources, in addition to the positive meaning and knowledge resources (work experience).

\section{Abusive Supervision}

It is defined as a "subordinate's perception of the extent to which supervisors engage in a sustained display of hostile, verbal, and non-verbal behaviors, excluding physical contact" (Zhang and Bednall, 2016, p. 455). According to the theory of affective events, researchers argue that abusive supervision is negatively associated with thriving (Luo, 2016). Employees perceive abusive supervision as a negative affective event that undermines the climate of trust and respect; a climate that ensures employee safety and encourages them to take risks and explore. Without this, employees can feel untrusted or disrespected and can lose their energy and enthusiasm for learning at work. Therefore, we propose the following hypothesis:

H II-1: Abusive supervision is negatively related to thriving at work.

\section{Authentic Leadership}

It is a specific leadership style that focuses on the self-awareness and psychological capital of both workplace leaders and followers (Gardner et al., 2005). Under this kind of leadership, leaders driven by their own values and beliefs provide more support to their staff and pursue an equal work environment (Gardner et al., 2005). Therefore, a positive relationship may exist between authentic leadership and employee thriving. Xu et al. (2017) emphasize this finding by highlighting a positive association between authentic leadership and thriving, especially through the meditating variable of leader-member exchange (LMX). LMX improves communication and interaction from the team level to an individual level, so that authentic leaders can influence their followers, in supervisory interactions, by increasing an 
inherent motivation for self-determination (Ryan and Deci, 2000). Therefore, we propose the following hypothesis:

H II-2: Authentic leadership is positively related to thriving at work.

\section{Empowering Leadership}

Unlike authentic leadership, empowering leadership emphasizes delegation to subordinates to improve their psychological experience at work ( $\mathrm{Li}$ et al., 2016). Delegation is a process of power-sharing, whereby employees have flexibility in decisionmaking, setting goals, or completing tasks. Simultaneously, they are more likely to feel motivated to learn on their own as they realize more responsibility and confidence from their leader (Ali et al., 2018). Empowered employees tend to shoulder more responsibilities than originally required (Kabat-Farr and Cortina, 2017). In the process, they are vitalized and become willing to learn to improve their work performance. Along with this opinion, Li et al. (2016) also proposed that empowering leadership engenders thriving. Specifically, this leadership style contributes to a greater tendency for employees to thrive, by encouraging them to participate in decision-making processes and providing many supportive resources. As a result, employees are highly willing to learn, stay vitalized, and feel more secure and responsible at work (Han, 2017). Therefore, we propose the following hypothesis:

H II-3: Empowering leadership is positively related to thriving at work.

\section{Leader-Member Exchange}

It refers to a particular relationship between leaders and their subordinates built via exchanges at work. Atwater and Carmeli (2009) concluded that the higher the quality of LMX, the more employees engage, and the more willing they are to be active and passionate at work because they feel trusted and respected. In short, harmonious LMX leads to employee thriving and improves work outcomes (Li, 2015; Xu et al., 2017). Zhang et al., (2018) drew a similar conclusion that LMX facilitates emotional bonding between leaders and their subordinates beyond the simpler relationship between the colleagues. This bond enhances the efficiency of employees, encourages engagement, brings vitality, and promotes learning. Thus, high-quality LMX between leaders and employees beneficially facilitates their work efficiency and enriches their job content (Atwater and Carmeli, 2009; Zhang et al., 2018). Therefore, we propose the following hypothesis:

H II-4: LMX is positively related to thriving at work.

\section{Servant Leadership}

Previous studies have suggested that there is a strong relationship between servant leadership and thriving at work (e.g., Jaiswal and Dhar, 2017; Walumbwa et al., 2018). Servant leadership is a positive leadership approach, focusing on serving colleagues and supporting them via necessary work resources and compassion. This empowers employees to take on challenges and be confident in continuously improving themselves (Walumbwa et al., 2018). Furthermore, servant leadership can lead to employee trust in leadership and enhance creativity in thriving (Jaiswal and Dhar,
2017). Luo (2016) revealed a positive correlation between servant leadership and thriving by investigating the effect of aggressive mistreatment by customers on employee thriving. Therefore, we propose the following hypothesis:

H II-5: Servant leadership is positively related to thriving at work.

\section{Transformational Leadership}

It exists when leaders actively stimulate employee motivation and help them achieve higher goals (Collins, 2014). The relationship between thriving and transformational leadership has recently attracted attention, and current empirical evidence has proven to be very positive (Dong, 2018). Transformational leadership enables employees to experience beneficial encouragement, happiness, and openness at work while encouraging them to feel more autonomous in a respectful and supportive environment. This collectively leads to the thriving of individual employees (Hildenbrand et al., 2018). Furthermore, this leadership style motivates employees to learn and increase vitality via social capital. Niessen et al. (2017) shed light on the relationship between the perceived transformational leadership and the thriving of teachers. Although they did not conclude a direct relationship between them and revealed that employees felt increased levels of thriving under strong transformational leadership, given that they were less emotionally exhausted. Therefore, we propose the following hypothesis:

H II-6: Transformational leadership is positively related to thriving at work.

In addition to various types of leadership, also known as relational resources (Spreitzer et al., 2005), two types of resources were meta-reviewed: positive meaning and knowledge resources (work experience).

\section{Positive Meaning}

It involves both the purpose and significance of work. It comes from the value of work and the creation of worth via interacting with colleagues at work (Spreitzer et al., 2005). Positive meaning at work aligns the expectations of employees to each other and also helps them to understand the goals of the organization. It enables them to understand their work and its significance and engenders thriving at work. Niessen et al. (2012) conducted a diary study and showed a positive relationship between personal variability during workdays and positive meaning and thriving. Their study provides evidence for a number of hypotheses for the socially embedded model of thriving proposed by Spreitzer et al. (2005), and expands the literature by focusing on identifying personal differences in positive meaning in a single day alone rather than concentrating on personal growth- and work-related outcomes. Individuals who experience a stronger sense of positive meaning at work will feel a sense of thriving on the same day. Therefore, we propose the following hypothesis:

$\mathrm{H}$ II-7: Positive meaning is positively related to thriving at work. 


\section{Work Experience}

In the model of Spreitzer et al. (2005), knowledge resources are known as the important resources generated at work that engender employee thriving. We argue that work experience is a knowledge resource because it is generated at work and enables employees to understand their work; in other words, it is related to the knowledge required and how to obtain the relevant information to get the job done (Moreland and Argote, 2003). Therefore, we expect that work experience serves as a knowledge resource for employees to learn about how to acquire the knowledge, information, and skills needed to work and promote thriving. Therefore, we propose the following hypothesis:

H II-8: Work experience is positively related to thriving at work.

\section{Individual Agentic Work Behaviors}

Also known as the engine of thriving (Spreitzer et al., 2005), agentic work behaviors include exploration, task focus, and heedful relating, and have significant effects on the thriving of an individual. This section focuses on the effects of these three behaviors on thriving.

\section{Exploration}

It is a phenomenon in which individuals seek new ways of working, via experimentation, discovery, innovation, and risktaking (Spreitzer et al., 2005). Previous studies have evidenced the positive relationship between exploration and thriving (Button et al., 1996). Spreitzer et al. (2005) posited that, when employees experienced explore at work, they were willing to acquire new knowledge to resolve problems, therefore positively related to the thriving of an employee. Exploration behavior also enhances employee vitality; Kleine et al. (2019) stated that exploration is a direct outcome of thriving as the activity is associated with the immediate experience of both vitality and learning. Sia and Duari (2018) evidenced the positive result of thriving by finding that work exploration stimulates employees to produce surprising ideas and strategies. Therefore, we propose the following hypothesis.

H III-1: Exploration is positively related to thriving at work.

\section{Task Focus}

Although the importance of heedful relating has attracted much attention, it is also essential, in investigating thriving at work, to analyze individual work task characteristics such as task focus. Task focus refers to the dedication and concentration required by an employee to achieve the objectives of a job (Brown et al., 2005). Niessen et al. (2012) concluded that task focus is a key agentic work behavior that plays an important role in increasing employee thriving. Specifically, highly dedicated employees focus on completing tasks and finding the best possible solutions, resulting in a higher likelihood of success and molding them into vital, active-learning employees. Employees who are highly task-focused feel a sense of accomplishment at work and actively acquire, previously unknown, integral job skills; thereby increasing thriving (Paterson et al., 2014). Furthermore, Paterson et al. (2014) found that, to thrive in a variety of job roles, employees adopt various behaviors depending on the scenario. People tend to be attracted to work by the tasks involved in the job, ergo, and are inclined to feel more vitality from these tasks and actively learn what is necessary to complete them (Sia and Duari, 2018). Therefore, we propose the following hypothesis.

H III-2: Task focus is positively related to thriving at work.

\section{Heedful Relating}

It refers to cooperative and mutually supportive interactions between the workers (Paterson et al., 2014). Many people work in advanced teamwork-based organizations, where collaboration and communication with teammates significantly affect employee thriving. In this case, the focus is on the interactions within the group and the achievements of the entire team. More effective and high-quality cooperation between the employees, that is, more heedful relating, engenders higher levels of thriving (Paterson et al., 2014). Heedful relations between colleagues are important for employees to fully realize the functions of the organizational structure and the ultimate goals of the organization. Through intensive and high-quality interactions, employees tend to actively learn from their colleagues and play responsible, larger roles in the team, ultimately increasing their levels of thriving (Sia and Duari, 2018). Abid et al. (2016) conducted an empirical study in support of the positive effects of heedful relations and posited that heedful relating motivates positive employee behavior, which is consistent with previous arguments. Therefore, we propose the following hypothesis:

$\mathrm{H}$ III-3: Heedful relating at work is positively related to thriving at work.

\section{Personality Traits}

In addition to the above antecedents in the model of thriving by Spreitzer et al. (2005) and Kleine et al. (2019) meta-analyzed several types of personality traits such as core self-evaluation and proactive personality. For this study, we meta-analyzed the relationship between the other four types of personality traits and thriving at work to complement the models of Spreitzer et al. (2005) and Kleine et al. (2019).

\section{Self-Efficacy}

It implies having an optimistic attitude toward difficulties and hurdles (Geiger, 2013). The relationship between self-efficacy and thriving has recently attracted attention as evidencing significantly positive effects on thriving, regardless of employee group (Geiger, 2013; Lee et al., 2015; Chen et al., 2016; Levy, 2016; Bensemmane et al., 2018; Zhu et al., 2019). Building self-efficacy, as a part of intrinsic mindfulness, increases the likelihood of employees thriving regardless of workplace characteristics, including the organizational climate (Geiger, 2013). Moreover, employees with high self-efficacy are ready to face the challenges at work and are confident enough to complete them. Thus, as self-efficacy accumulates, employees are more likely to feel that they are thriving regardless of the work environment (Levy, 2016). Bensemmane et al. (2018) discovered this relationship in the context of a team and proposed that 
self-efficacy is integral to understanding the importance and effectiveness of personal resources. Therefore, we propose the following hypothesis.

H IV-1: Self-efficacy is positively related to thriving at work.

\section{Optimism}

It is a personality trait that refers to the ability to positively associate events with outcomes (Luthans et al., 2007). Similar to the analytical path of self-efficacy, Levy (2016) agreed that optimism encourages employees to focus on their work, which increases the likelihood of meeting the job requirements and completing difficult tasks, thereby contributing to their experience of thriving. Xie (2015) also proposed that optimism is one of the four components of psychological capital. Employees are believed to thrive more from frustration when they use psychological capital, such as the patience and courage offered by optimism, to manage challenges or to face unfair treatment. Furthermore, optimistic employees accept challenges, with confidence and a positive attitude, making them less likely to be influenced by anxiety or anger. Thus, they gain more positive outcomes such as thriving (Cheng et al., 2013). Therefore, we propose the following hypothesis.

$\mathrm{H}$ IV-2: Optimism is positively related to thriving at work.

\section{Openness}

Employees who are open tend to show positive emotions and also tend to be active and energetic at work. Additionally, open-minded employees are modest and inherently learn from their surroundings (Hennekam, 2017) and, therefore, experience higher levels of thriving. The interaction between being open to experience and transformational leadership also affects employee thriving (Hildenbrand et al., 2018). In the context of leadership, people who are open are able to cope with opposing voices and to avoid serious embarrassment at work, thus supporting them to thrive. By analyzing the underlying mechanisms, we propose the following hypothesis.

H IV-3: Openness is positively related to thriving at work.

\section{Conscientiousness}

It describes the ability of an individual to maintain self-discipline and continued motivation to achieve goals (Costa et al., 1991), and has been found to positively influence employee thriving. Conscientious employees tend to behave well and work hard toward their goals as they are familiar with their work and job contents (Hennekam, 2017). Simultaneously, this ability leads to outperformance and provides a sense of accomplishment. Therefore, conscientious employees tend to thrive easily (Hennekam, 2017). Conscientiousness also expresses a sense of responsibility that helps employees motivate themselves to thrive, and the employees tend to work more eagerly and broadly, laying a foundation for the emergence of thriving (Xie, 2015). Therefore, we propose the following hypothesis.

H IV-4: Conscientiousness is positively related to thriving at work.

\section{The Moderating Effects of National Culture}

Most research on management specifies national culture as an import contingent factor that influences the relationships between different variables (Rattrie et al., 2020). For example, it serves as an important contextual factor that will influence the relationships between some work-related antecedents and outcomes (e.g., Choi et al., 2015, personality traits and organizational commitment). The dimensions of national culture were also regarded as influential factors that determine the responses of individuals toward work conditions and subsequently the associated results of the work (Liu et al., 2007; Taras et al., 2010, 2011). According to his research on national culture, Hofstede (1984) identified individualism as an important characteristic of each country and revealed the contrast in the scores of individualism between Eastern, primarily Asian countries, and Western countries. Compared to China with a score of being 20, the United States had a much higher score of 91 (Hofstede, 2001). Several studies are consistent with this result, including the regulatory focus theory of Higgins (1997) as well as the other relevant disparities between the scores.

Among the dimensions of national culture, individualism/collectivism dimension was considered as one of the important factors that cause the deviation of the reactions of individuals toward different job characteristics (e.g., Spector et al., 2007) and that of the different levels of their commitment to the organizations (Parkes et al., 2001). Individuals with an interdependent self-construal, in low-level individualistic countries, actively respond to information about accepting, or avoiding, responsibility for their surroundings; whereas, those with an independent self-construal, in highlevel individualistic countries, tend to react to information in terms of personal goals and objectives (Lee et al., 2000; Elliot et al., 2001; Xu et al., 2018). Citizens living in high-scoring, individualistic countries tend to prioritize their interests, and set themselves apart from others. Therefore, the relationship between antecedents and thriving varies depending on the levels of individualistic culture.

According to the socially embedded model of thriving, the thriving of an individual is not only self-driven but also occurs through his/her interactions with others (Brown and Duguid, 1991; Wenger, 1998). Low-level individualistic countries emphasize the importance of collective interests in a group level and encourage individuals to support each other and maintain harmonious relationships. Individuals in low-level individualistic countries "are integrated into strong, cohesive in-groups, which throughout people's lifetime continue to protect them in exchange for unquestioning loyalty" (Hofstede, 2001, p. 225). Ronen and Mikulincer (2009) also stated that individuals in low-level individualistic cultures were more sensitive to the fulfillment of group goals, the completion of teamwork, and the improvement engagement in a group level (Rattrie et al., 2020). This necessary interaction brought by the teamwork among individuals, via culture, is more likely to facilitate employee thriving in benign work environments, with positive work unit contextual features and resources. Therefore, we propose the following hypothesis. 
$\mathrm{H} \mathrm{V}$ : The relationship between antecedents and employee thriving is stronger in the countries with low-level of individualism than in the countries with high-level of individualism.

\section{METHODS}

\section{Search Strategy}

To identify the empirical studies on thriving at work for use in the meta-analysis, we followed the search procedures in other metaanalysis (e.g., Zhang et al., 2017) and employed the following strategy to locate appropriate articles. Firstly, we conducted a computer-based search in the databases, including Web of Science (SSCI), EBSCO, ABI/INFORM, ERIC, PsycINFO, Google Scholar, and Scopus by filtering the date prior to 2019, and using the keywords "work" and "thriving" or two dimensions of thriving, namely "vitality" and "learning." We also search for the articles containing the term ““工作繁荣” 和 “工作旺盛感” ” in China National Knowledge Infrastructure (CNKI), which is the most commonly used database for searching Chinese academic publications. Secondly, we manually searched for recent empirical articles that address thriving via qualitative and/or quantitative review (Kleine et al., 2019). For unpublished studies, we took four search approaches into dissertations, reports, book chapters, working papers, and conference papers. Firstly, dissertations were searched for in the ProQuest databases. Secondly, book chapters, working papers, and conference papers were searched for on Scopus and Web of Science. Finally, we distributed the information about our meta-analysis on the service lists of the Human Resources and Organizational Behavior Divisions at the Academy of Management conference and extracted additional working papers on thriving at work.

\section{Inclusion and Exclusion Criteria}

The following procedure was used to identify the eligible studies that could be used for meta-analysis. Firstly, empirical studies must include the variable to be focused on, that is thriving at work, and must be categorized within the discipline of management. Secondly, at least one of the antecedents for thriving, from the current model, must be included in the study. Thirdly, thriving must be measured empirically with the reported correlations between thriving at work and its antecedents. Finally, 67 current studies $(N=28,097)$ were included in the final sample.

\section{Coding Procedures}

Prior to the coding process, two researchers of this study developed a coding scheme according to Krippendorff (2013) to guarantee consistency between different coders. Specifically, to decrease the inconsistency of the concepts among the antecedents, which are similar but termed in different forms (e.g., challenge stress/challenging stress), two coders had a discussion with each other to ensure the consistency of a related term in the coding scheme. In addition, concepts such as "challenge demand" in some papers were coded as challenge stress as these two constructs fully resemble each other. In this study, as shown in Table 2, similar constructs are used to describe specific antecedents. Next, according to this scheme, two coders independently coded the data from the selected empirical studies. The coded information for each study included: (1) the correlations between thriving and its antecedents, (2) the sample size, (3) Cronbach's alpha of thriving and its antecedents, and (4) the moderators, which specify the countries, wherein each study was conducted. After completing their task, each coder independently checked the coding sheets of each other, and in case of existence of any inconsistencies, the disagreement was discussed and addressed. The inter-rater reliability of the two coders was high (Cohen's kappa $=0.88$ ).

\section{Sample Information}

Most of the empirical studies were conducted in China and the United States, which account for 50 and $7.81 \%$, respectively. The samples included male and female participants with the percentage of men being greater than $50 \%$ accounting for $61.40 \%$, and women being greater than $50 \%$ accounting for $38.6 \%$. Most of the research subjects were in the range of $30-40$ years old. Details about each sample are shown in Table 3.

\section{Publication Bias}

Two methods were used to expose the publication bias in the analysis. Firstly, we used the fail-safe N of Rosenthal (1979) as a measure of the number of existing, unpublished studies needed to transform a significant population effect size estimate into a non-significant result. Table 4 shows the results of all the fail-safe Ns for each bivariate relationship in this study. On an average, our sample had a fail-safe $N$ of 893.5 , suggesting that 893.5, or more, unpublished studies should be included in the analysis to reduce the size of the population effect to a non-significant level. Secondly, after deriving the number of unreleased publications needed to change the result, we calculated if it was actually influenced by a publication bias. In Begg and Mazumdar (1994), the Kendall rank correlation coefficient was used to test the effect on the significance of the results. As shown in Table 4, the nonsignificant Kendall rank correlation coefficient indicates that all relationships are independent of publication bias. These results show that most of the tested correlations (24 out of 24 , i.e., $100 \%$ ) are not influenced by publication bias.

\section{Analysis}

A random effects model was implemented to test hypotheses I-IV, which were proposed to describe the relationships between thriving and its outcomes. In Hunter and Schmidt (2004), an approach to psychometric meta-analysis was used as it considers, in the field of organizational behavior, the influence of artifacts such as measurement error-a common issue in psychometric empirical research. Regarding the mean effect, we report the independent effect size $(k)$, sample size $(N)$, and weighted mean correlation $(r)$. We also report mean true-score correlation $(\bar{\rho})$; and observe SDs of corrected correlations [SD_(r_c)], residual SDs of $\rho$ (SD_ $\rho$ ), the $95 \%$ CI for the main effect, and the variability of corrected effect size estimates investigated by calculating $80 \%$ credibility intervals.

As mentioned and according to the previous research on cross-cultural meta-analysis, national culture has various 
TABLE 2 | Summary of similar constructs used to identify specific antecedents.

\begin{tabular}{|c|c|}
\hline Antecedents & Similar constructs \\
\hline \multicolumn{2}{|l|}{ Unit contextual features } \\
\hline \multirow[t]{3}{*}{ Challenge stress } & Challenge stress \\
\hline & Challenge demand \\
\hline & Challenge appraisal \\
\hline \multirow[t]{6}{*}{ Hindrance stress } & Hindrance stress \\
\hline & Hindrance demand \\
\hline & Hindrance appraisal \\
\hline & Role ambiguity \\
\hline & Role overload \\
\hline & Time pressure \\
\hline \multirow[t]{7}{*}{ Autonomy } & Autonomy \\
\hline & Work autonomy \\
\hline & Autonomy orientation \\
\hline & Decision-making authority \\
\hline & Autonomous motivation \\
\hline & Flexibility-autonomy \\
\hline & Need for autonomy \\
\hline \multirow[t]{3}{*}{ Work control } & Work control \\
\hline & Job control \\
\hline & Sense of work control \\
\hline \multirow[t]{5}{*}{ Trust } & Trust \\
\hline & Trust in leader \\
\hline & Trust in Colleagues \\
\hline & Trust in Supervisor \\
\hline & Interpersonal trust \\
\hline \multirow[t]{3}{*}{ Supportive climate } & Supportive climate \\
\hline & Supportive supervising style \\
\hline & Team-learning climate \\
\hline \multirow[t]{3}{*}{ Organizational justice } & Organizational justice \\
\hline & Fairness Perception \\
\hline & Average transient overall team justice \\
\hline \multirow[t]{3}{*}{ Feedback } & Supervisor feedback \\
\hline & Feedback-seeking behavior \\
\hline & Supervisor developmental feedback \\
\hline Job crafting & Job crafting \\
\hline \multicolumn{2}{|l|}{$\begin{array}{l}\text { Resource produced } \\
\text { at work }\end{array}$} \\
\hline \multirow[t]{3}{*}{ Abusive supervision } & Abusive supervision \\
\hline & Abusive management \\
\hline & Workplace violence \\
\hline Authentic leadership & Authentic leadership \\
\hline \multirow[t]{2}{*}{ Empowering leadership } & Empowering leadership \\
\hline & Empowerment \\
\hline \multirow[t]{6}{*}{ LMX } & Leader-member exchange \\
\hline & LMX \\
\hline & LMX quality \\
\hline & Supervisor-subordinate relationship \\
\hline & Leader relational behaviors \\
\hline & Social exchange \\
\hline Servant leadership & Servant leadership \\
\hline \multirow{2}{*}{$\begin{array}{l}\text { Transformational } \\
\text { leadership }\end{array}$} & Transformational leadership \\
\hline & Perceived transformational leadership \\
\hline
\end{tabular}

(Continued)
TABLE 2 | Continued

\begin{tabular}{ll}
\hline Antecedents & Similar constructs \\
\hline Positive meaning & Positive meaning \\
Work experience & Experience \\
& Work experience \\
& Number of organizations one has worked in \\
Personal traits & Self-efficacy \\
Self-efficacy & Average transient self-efficacy \\
& Innovation self efficacy \\
& Job self-efficacy \\
Optimism & Optimism \\
Openness & Openness \\
& Openness to experience \\
Conscientiousness & External work contacts \\
Individual agentic & Conscientiousness \\
work behaviors & \\
Exploration & Exploration \\
Task focus & Active exploration \\
Heedful relating & Task focus \\
& Concentration \\
& Heedful relating \\
&
\end{tabular}

moderating effects on the results of this study (e.g., Liu et al., 2016). The website of Geert Hofstede ${ }^{1}$ displays the national scores, calculated by representative country samples, from the World Values Survey. These scores were assigned in an ascending order from 0 to 100 to accurately measure the individualism culture dimension. These scores were then matched according to the samples in our meta-analysis. The final step was to conduct a meta-regression (Borenstein et al., 2009) to test the significance of the moderating effect of longterm orientation.

\section{RESULTS}

\section{The Influence of Work Unit Contextual Features on Thriving}

From $\mathrm{H} \mathrm{I}-1$ and $\mathrm{H} \mathrm{I}-2$, it is inferred that unit contextual features such as hindrance stress are negatively related to thriving at work. In Contrast, challenge stress is positively related to thriving at work. As shown in Table 5, challenge stress $(\bar{\rho}$ $=0.46 ; \mathrm{H} \mathrm{I}-1)$ is positively associated with thriving, and hindrance stress $(\bar{\rho}=-0.19$; H I-2) is negatively associated with thriving.

From $\mathrm{H} \mathrm{I}-3$ and $\mathrm{H} \mathrm{I}-4$, it is inferred that that autonomy $(\bar{\rho}=0.49 ; \mathrm{H} \mathrm{I}-3)$ and work control $(\bar{\rho}=0.26$; H I- 4$)$ are moderately and positively related to thriving at work. All 95\% CIs exclude zero. Therefore, H I-3 and H I-4 are supported.

From the hypotheses $\mathrm{H} \mathrm{I}-5$ to $\mathrm{H} \mathrm{I}-9$, it is inferred that trust, supportive climate, organizational justice, feedback, and job

\footnotetext{
${ }^{1}$ https://www.hofstede-insights.com/country/china/
} 
TABLE 3 | Summary of sample information.

\begin{tabular}{|c|c|}
\hline Category & Percentages \\
\hline \multicolumn{2}{|l|}{ Gender ( $\%$ of male) } \\
\hline$<=50 \%$ & $61.40 \%$ \\
\hline$>50 \%$ & $38.60 \%$ \\
\hline \multicolumn{2}{|l|}{ Average age } \\
\hline$>20$ and $\leq 30$ & $24.14 \%$ \\
\hline$>30$ and $\leq 40$ & $44.83 \%$ \\
\hline$>40$ and $\leq 50$ & $27.59 \%$ \\
\hline$>50$ & $3.45 \%$ \\
\hline \multicolumn{2}{|l|}{ Country } \\
\hline Austria (Central Europe) & $1.56 \%$ \\
\hline Belgium (Central Europe) & $1.56 \%$ \\
\hline Canada & $4.69 \%$ \\
\hline China & $50.00 \%$ \\
\hline Finland & $1.56 \%$ \\
\hline France & $1.56 \%$ \\
\hline Germany (Central Europe) & $4.69 \%$ \\
\hline India & $3.13 \%$ \\
\hline Indonesia & $1.56 \%$ \\
\hline Israel & $6.25 \%$ \\
\hline Korea & $1.56 \%$ \\
\hline Netherlands & $3.13 \%$ \\
\hline Pakistan & $3.13 \%$ \\
\hline South Africa & $3.13 \%$ \\
\hline Taiwan & $1.56 \%$ \\
\hline Turkey & $1.56 \%$ \\
\hline United States & $7.81 \%$ \\
\hline Worldwide & $1.56 \%$ \\
\hline
\end{tabular}

crafting is positively related to thriving. As shown in Table 5, trust $\bar{\rho}=(0.49 ; \mathrm{H} \mathrm{I}-5)$, supportive climate $(\bar{\rho}=0.40$; H I-6), organizational justice $(\bar{\rho}=0.67 ; \mathrm{H} \mathrm{I}-7)$, feedback $(\bar{\rho}=0.62 ; \mathrm{H}$ I-8), and job crafting ( $\bar{\rho}=0.61$; H I-9) have moderate to strong, positive effects on thriving as all $95 \%$ CIs exclude zero. Therefore, H I-5 to H I-9 are supported.

\section{The Influence of Resources Produced at Work, on Thriving}

H II-1 proposes that negative leadership such as abusive supervision is negatively related to thriving. As shown in Table 5, abusive supervision is negatively associated with thriving $(\bar{\rho}$ $=-0.21, \mathrm{H}$ II-1). H II-1 is supported because the $95 \%$ CIs of these estimated relationships exclude zero. H II-2 to H II-6 propose that positive leadership, including authentic, empowered, servant, and transformational leaderships, as well as LMX and trust, is positively related to thriving. As shown in Table 5, authentic leadership ( $\bar{\rho}=0.38$; H II-2), empowered leadership $(\bar{\rho}=0.47$; H II-3), LMX ( $\bar{\rho}=0.59$; H II-4), servant leadership $\bar{\rho}=0.49$; H II-5), and transformational leadership $(\bar{\rho}=0.46 ; \mathrm{H}$ II-6) are moderately and positively correlated with thriving as all 95\% CIs exclude zero. Therefore, H II-2 to H II-6 are supported.
TABLE 4 | The results of publication bias test.

\begin{tabular}{|c|c|c|c|c|c|}
\hline Antecedents & $k$ & $N$ & $\begin{array}{c}\text { Classic } \\
\text { Fail-safe } N\end{array}$ & $\begin{array}{c}\text { Kendall's } \\
\text { Tau }\end{array}$ & $\boldsymbol{P}$ \\
\hline \multicolumn{6}{|l|}{ Unit contextual features } \\
\hline Challenge stress & 6 & 2,580 & 669 & -0.27 & 0.452 \\
\hline Hindrance stress & 9 & 5,610 & 435 & 0 & 1 \\
\hline Autonomy & 11 & 3,883 & 3679 & -0.121 & 0.583 \\
\hline Work control & 7 & 3,161 & 680 & 0.19 & 0.548 \\
\hline Trust & 8 & 2,418 & 882 & -0.07 & 0.851 \\
\hline Supportive climate & 5 & 2,176 & 271 & -0.67 & 0.296 \\
\hline Organizational justice & 3 & 1,013 & 553 & -0.33 & 0.601 \\
\hline Feedback & 5 & 2,423 & 1931 & 0 & 1 \\
\hline Job crafting & 3 & 803 & 534 & -0.33 & 0.601 \\
\hline \multicolumn{6}{|c|}{ Resources produced at work } \\
\hline Abusive supervision & 3 & 1,602 & 55 & -0.67 & 0.296 \\
\hline Authentic leadership & 5 & 1,819 & 54 & 0.33 & 0.601 \\
\hline Empowering leadership & 6 & 2,364 & 167 & 0 & 1 \\
\hline LMX & 9 & 2,871 & 2636 & -0.25 & 0.348 \\
\hline Servant leadership & 5 & 2,028 & 271 & -0.67 & 0.296 \\
\hline Transformational leadership & 6 & 2,121 & 882 & -0.07 & 0.851 \\
\hline Positive meaning & 4 & 631 & 320 & -0.1 & 0.81 \\
\hline Work experience & 6 & 2,537 & 8 & 0.5 & 0.22 \\
\hline \multicolumn{6}{|c|}{ Individual agentic work behaviors } \\
\hline Exploration & 3 & 509 & 536 & -0.8333 & 0.089 \\
\hline Task focus & 6 & 1,751 & 1373 & -0.13 & 0.707 \\
\hline Heedful relating & 12 & 3,149 & 121 & 0.1 & 0.806 \\
\hline \multicolumn{6}{|l|}{ Personality traits } \\
\hline Self-efficacy & 9 & 3,606 & 1580 & 0.107 & 0.711 \\
\hline Optimism & 4 & 1,856 & 1109 & 0.17 & 0.734 \\
\hline Openness & 3 & 1,470 & 1109 & 0.17 & 0.734 \\
\hline Conscientiousness & 5 & 2,702 & 599 & 0.1 & 0.807 \\
\hline
\end{tabular}

$k$, the number of independent effect sizes included in each analysis; $N$, the number of participants in each analysis; Classic fail-safe $N$, the number of unpublished studies it will take to raise the $p$-value to an insignificant level; Kendall's Tau, Kendall rank correlation coefficient; $p$, the $p$-value for Kendall rank correlation coefficient.

H II-7 proposes that positive meaning is positively related to thriving. As shown in Table 5, positive meaning $(\bar{\rho}=0.53)$ is moderately and positively correlated with thriving as all $95 \%$ CIs exclude zero. H II- 8 proposes that work experience, as one type of knowledge resources, positively influences thriving. The results in Table 5 show that work experience $(\bar{\rho}=0.05)$ is not related to thriving as the $95 \%$ CIs include zero. Therefore, $\mathrm{H} \mathrm{II-7}$ and $\mathrm{H}$ II-8 are partially supported.

\section{The Influence of Individual Agentic Work Behaviors on Thriving}

$\mathrm{H}$ III-1 to $\mathrm{H}$ III-3 propose that individual agentic work behaviors are positively related to thriving. The results in Table 5 indicate that exploration $(\bar{\rho}=0.66 ; \mathrm{H}$ III-1), task focus $(\bar{\rho}$ $=0.63 ; \mathrm{H}$ III- 2$)$, and heedful relating $(\bar{\rho}=0.52 ; \mathrm{H}$ III3 ) have moderate to strong, positive correlations with thriving as all 95\% CIs exclude zero. Therefore, $\mathrm{H}$ III-1 to H III3 are supported. 
TABLE 5 | Meta-analysis of relationships between thriving at work and its antecedents.

\begin{tabular}{|c|c|c|c|c|c|c|c|c|c|c|}
\hline Antecedents & $k$ & $N$ & $\bar{r}$ & $S D_{r}$ & $\mathrm{SD}_{\text {res }}$ & $\bar{\rho}$ & $\mathrm{SD}_{\mathrm{rc}}$ & $S_{p}$ & $95 \% \mathrm{Cl}$ & $80 \%$ CR \\
\hline \multicolumn{11}{|l|}{ Unit contextual features } \\
\hline Challenge stress & 6 & 2,580 & 0.39 & 0.18 & 0.18 & 0.46 & 0.19 & 0.19 & $(0.30,0.61)$ & $(0.22,0.70)$ \\
\hline Hindrance stress & 9 & 5,610 & -0.17 & 0.11 & 0.10 & -0.19 & 0.12 & 0.11 & $(-0.27,-0.11)$ & $(-0.33,-0.04)$ \\
\hline Autonomy & 11 & 3,883 & 0.42 & 0.18 & 0.17 & 0.49 & 0.20 & 0.19 & $(0.38,0.61)$ & $(0.25,0.74)$ \\
\hline Work control & 7 & 3,161 & 0.21 & 0.29 & 0.29 & 0.26 & 0.34 & 0.34 & $(0.00,0.51)$ & $(-0.18,0.69)$ \\
\hline Trust & 8 & 2,418 & 0.35 & 0.16 & 0.15 & 0.49 & 0.20 & 0.19 & $(0.35,0.62)$ & $(0.25,0.72)$ \\
\hline Supportive climate & 5 & 2,176 & 0.35 & 0.15 & 0.16 & 0.40 & 0.17 & 0.16 & $(0.26,0.54)$ & $(0.19,0.60)$ \\
\hline Organizational justice & 3 & 1,013 & 0.59 & 0.16 & 0.15 & 0.67 & 0.16 & 0.15 & $(0.49,0.84)$ & $(0.47,0.86)$ \\
\hline Feedback & 5 & 2,423 & 0.53 & 0.12 & 0.12 & 0.62 & 0.14 & 0.14 & $(0.50,0.75)$ & $(0.45,0.80)$ \\
\hline Job crafting & 3 & 803 & 0.51 & 0.06 & 0.03 & 0.61 & 0.09 & 0.07 & $(0.51,0.71)$ & $(0.52,0.70)$ \\
\hline \multicolumn{11}{|c|}{ Resources produced in doing of work } \\
\hline Abusive supervision & 3 & 1,602 & -0.17 & 0.06 & 0.05 & -0.21 & 0.07 & 0.05 & $(-0.29,-0.13)$ & $(-0.27,-0.15)$ \\
\hline Authentic leadership & 5 & 1,819 & 0.32 & 0.19 & 0.18 & 0.38 & 0.22 & 0.21 & $(0.19,0.57)$ & $(0.11,0.65)$ \\
\hline Empowering Leadership & 6 & 2,364 & 0.39 & 0.15 & 0.14 & 0.47 & 0.16 & 0.15 & $(0.35,0.60)$ & $(0.28,0.66)$ \\
\hline LMX & 9 & 2,871 & 0.49 & 0.13 & 0.12 & 0.59 & 0.15 & 0.14 & $(0.50,0.69)$ & $(0.42,0.77)$ \\
\hline Servant leadership & 5 & 2,028 & 0.39 & 0.10 & 0.09 & 0.49 & 0.12 & 0.10 & $(0.40,0.59)$ & $(0.36,0.62)$ \\
\hline Transformational leadership & 6 & 2,121 & 0.42 & 0.19 & 0.19 & 0.46 & 0.21 & 0.21 & $(0.29,0.64)$ & $(0.20,0.73)$ \\
\hline Positive meaning & 4 & 631 & 0.46 & 0.07 & 0.04 & 0.53 & 0.09 & 0.06 & $(0.44,0.62)$ & $(0.45,0.60)$ \\
\hline Work experience & 6 & 2,537 & 0.05 & 0.09 & 0.08 & 0.05 & 0.11 & 0.10 & $(-0.03,0.13)$ & $(-0.07,0.18)$ \\
\hline \multicolumn{11}{|c|}{ Individual agentic work behaviors } \\
\hline Exploration & 3 & 509 & 0.55 & 0.04 & 0.00 & 0.66 & 0.06 & 0.00 & $(0.59,0.73)$ & $(0.66,0.66)$ \\
\hline Task focus & 6 & 1,751 & 0.54 & 0.12 & 0.11 & 0.63 & 0.14 & 0.13 & $(0.52,0.74)$ & $(0.47,0.80)$ \\
\hline Heedful relating & 12 & 3,149 & 0.42 & 0.13 & 0.11 & 0.52 & 0.13 & 0.12 & $(0.45,0.59)$ & $(0.37,0.67)$ \\
\hline \multicolumn{11}{|l|}{ Personality traits } \\
\hline Self-efficacy & 9 & 3,606 & 0.41 & 0.16 & 0.15 & 0.48 & 0.16 & 0.15 & $(0.38,0.58)$ & $(0.28,0.68)$ \\
\hline Optimism & 4 & 1,856 & 0.54 & 0.03 & 0.01 & 0.65 & 0.05 & 0.03 & $(0.60,0.70)$ & $(0.62,0.69)$ \\
\hline Openness & 3 & 1,470 & 0.06 & 0.07 & 0.06 & 0.07 & 0.08 & 0.06 & $(-0.02,0.16)$ & $(-0.01,0.15)$ \\
\hline Conscientiousness & 5 & 2,702 & 0.35 & 0.14 & 0.13 & 0.40 & 0.14 & 0.14 & $(0.28,0.53)$ & $(0.23,0.58)$ \\
\hline
\end{tabular}

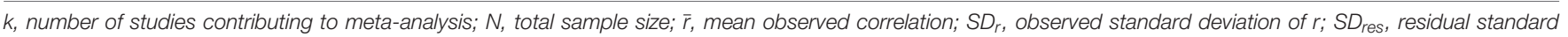

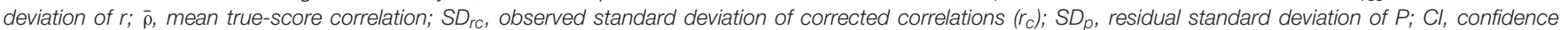
interval around $\bar{\rho}$; CR, credibility interval around $\bar{\rho}$. Correlations corrected individually.

\section{The Influence of Personality Traits on Thriving}

$\mathrm{H}$ IV-1 and $\mathrm{H}$ IV-2 propose that positive personality traits, including self-efficacy, optimism, openness, and conscientiousness, are positively related to thriving. As shown in Table 5, self-efficacy $(\bar{\rho}=0.48$; H IV- 1$)$, optimism $(\bar{\rho}=0.65$; H IV-2), and conscientiousness ( $\bar{\rho}=0.40 ; \mathrm{H} \mathrm{IV}-4)$ are positively correlated with thriving as all $95 \%$ CIs exclude zero. However, openness $(\bar{\rho}=0.07$; H IV-3) does not correlate with thriving as the $95 \%$ CIs include zero. Therefore, with the exception of $\mathrm{H}$ IV1-4, H IV-1, H IV-2, and H IV-4 are supported, but H IV-3 is not supported.

\section{The Moderating Effect of National Culture}

$\mathrm{H} \mathrm{V}$ proposes that the moderating effect of national culture on the relationship between thriving and its antecedents can be found in lower-level individualistic countries and that the relationship in the countries with lower levels of individualism is stronger than in the countries with higher levels of individualism. To test this hypothesis, a random meta-regression was employed to examine all moderating effects.

As shown in Table 6, unit contextual features and individualistic culture moderate the correlations between thriving at work, autonomy $(B=0.006, p<0.05)$, feedback $(B=0.026, p<0.01)$, organizational justice $(B=-0.01$, $p<0.01)$, and supportive climate $(B=0.006, p<0.05)$.

For leadership variables, individualistic cultures moderate the correlations between thriving and servant leadership $(B=0.011$, $p<0.01)$, and transformational leadership $(B=-0.09, p<0.01)$.

For individual agentic work behaviors, individualistic cultures moderate the correlation between thriving and exploration $(B=-0.01, p<0.01)$. Finally, for personality traits, individualistic cultures moderated the correlation between thriving and conscientiousness $(B=-0.005, p<0.01)$.

\section{DISCUSSION}

This study systematically and comprehensively meta-analyzes the relationship between antecedents and thriving at work according 
TABLE 6 | The moderating effect of national culture on the relationships between thriving at work and its antecedents.

\begin{tabular}{|c|c|c|c|}
\hline \multirow[t]{2}{*}{ Antecedents } & \multicolumn{3}{|c|}{ Individualism } \\
\hline & $\boldsymbol{k}$ & $B$ & SE \\
\hline \multicolumn{4}{|l|}{ Unit contextual features } \\
\hline Challenge stress & 6 & -0.03 & 0.004 \\
\hline Hindrance stress & 9 & 0.001 & 0.002 \\
\hline Autonomy & 11 & $0.006^{\star}$ & 0.003 \\
\hline Work control & 7 & -0.002 & 0.008 \\
\hline Trust & 6 & -0.011 & 0.009 \\
\hline Supportive climate & 4 & $0.006^{\star}$ & 0.003 \\
\hline Organizational justice & 3 & $-0.01^{* *}$ & 0.001 \\
\hline Feedback & 5 & $0.026^{\star \star}$ & 0.007 \\
\hline Job crafting & - & - & - \\
\hline \multicolumn{4}{|l|}{ Resources produced at work } \\
\hline Abusive supervision & - & - & - \\
\hline Authentic leadership & 3 & 0.003 & 0.002 \\
\hline Empowering Leadership & - & - & - \\
\hline LMX & 9 & 0.002 & 0.003 \\
\hline Servant leadership & 3 & $0.011^{\star *}$ & 0.003 \\
\hline Transformational leadership & 6 & $-0.09^{\star \star}$ & 0.003 \\
\hline Positive meaning & 4 & 0.001 & 0.001 \\
\hline Work experience & 5 & 0.000 & 0.001 \\
\hline \multicolumn{4}{|c|}{ Individual agentic work behaviors } \\
\hline Exploration & 3 & $-0.01^{\star \star}$ & 0.001 \\
\hline Task focus & 6 & 0.003 & 0.003 \\
\hline Heedful relating & 12 & -0.01 & 0.002 \\
\hline \multicolumn{4}{|l|}{ Personality traits } \\
\hline Self-efficacy & 8 & -0.001 & 0.002 \\
\hline Optimism & 4 & 0.002 & 0.002 \\
\hline Openness & 3 & 0.001 & 0.002 \\
\hline Conscientiousness & 5 & $-0.005^{\star \star}$ & 0.002 \\
\hline
\end{tabular}

$k$, number of samples in the regression analysis; $\beta$, regression coefficients; $p$, the $p$-value for the coefficient. Individualism scores were coded according to the dimension data matrix on Hofstede's website.

${ }^{*} p<0.05 ;{ }^{* *} p<0.01$.

to the socially embedded model of thriving by Spreitzer et al. (2005) and the research of Kleine et al. (2019). It illustrates the antecedent effects of thriving, including work unit contextual features, the resources produced at work, agentic work behaviors, and personality traits. It also examines the possible influence of individualistic cultural contexts on the correlations between thriving and its antecedents.

In our meta-analysis, we found that work unit contextual features, the resources produced at work, agentic work behaviors, and personality traits have a moderate to strong effect on thriving at work.

As to the unit contextual features, most of the constructs are found to be significantly correlated with employees' thriving at work. Among them, autonomy and work control are both positively related to the thriving of employees. Although some similarities are shared by both constructs, we believe there are still some discrepancies between these two concepts. Work control of employees refers to their control over their own work tasks and practices (Quick et al., 1990), which will benefit the working state of employees. However, autonomy focuses on more psychological experience of employees in improving their efficiency (Rhoades and Eisenberger, 2002), and will also promote employees' thriving at work. Indeed, job crafting also reflects a certain level of autonomy and control the work of individuals. All these results further confirm the vital role of motivational factors proposed in the hygiene-motivation theory (Herzberg et al., 1959).

In terms of resources produced at work, it seems that a welcomed leader plays an important role in increasing employees' thriving at work. According to the results, different styles of positive leadership (such as transformational leadership, authentic leadership, and empowering leadership) are believed to be positively correlated with employees' thriving at work. The conclusions resemble the results of most studies on leadershipthriving relationships (e.g., Collins, 2014; Mortier et al., 2016; Ali et al., 2018). Although it is not our research focus in this study, the differences in these effects across different leadership styles were not confirmed. If there do exist some differences, why these distinctions occur and what the mediation effects between the leadership-thriving relationship are needed to address in the following empirical studies. We fail to predict the relationship between work experience and thriving as we expected. It occurs probably because individuals with more experience are also the aged ones, who are not easily to be thrived in their work. The limited samples in the meta-analysis were considered to be another possible reason for this issue.

Individuals who act as an agent toward their work will be more thrived at work. Consistent with the point made by Spreitzer et al. (2005), exploration, task focus, and heedful relating are reported to be positively correlated with employees' thriving at work. Exploration indicates some exploratory behaviors (Button et al., 1996), which help individuals to be more thrived. Task focus enables individuals to be more concentrated on their tasks, and also to be more thrived (Ryan and Deci, 2000; Brown and Ryan, 2003). Meanwhile, heedful relating of individuals facilitates them to be energetic and studious ones by offering help to others and acquiring new skills (Spreitzer et al., 2005).

Personality traits (e.g., self-efficacy, optimism, and conscientiousness) are also the correlates of employees' thriving at work. Individuals with stable positive personality traits are more likely to be thriving at work. This was consistent with the results of those studies that focused on personality-related predictors of thriving at work (Ren et al., 2015). However, contrary to our expectations, openness was not related to thriving at work. The insignificant result might be also due to a small sample in the meta-analysis.

In addition, we found that the relationships between thriving and antecedents (autonomy, feedback, supportive climate, and servant leadership), which were supposed to provide employees with support and discretion, are stronger in a higher-level individualistic country. In contrast, the relationships between employees' thriving at work and antecedents (organizational justice and transformational leadership) that can represent the quality of the relationship between employees and colleagues, and antecedents (exploration and conscientiousness) that describe 
the self-characteristics of an individual are stronger in the lowerlevel individualistic cultures. The possible explanation might be that individuals tend to react to the information in terms of personal goals and objectives in individualistic countries, thus the enabling conditions, such as discretion and support that could help them better get job done, could more likely to encourage them to be thrived. In contrast, individuals in the collectivistic culture concerned more on the relationship with each other. Therefore, the indicators that could help them get well along with others could more likely to drive them thriving.

This study theoretically contributes to the existing literature with the following: Firstly, this research focuses on more categories of antecedents of employee thriving compared with the model of Kleine et al. (2019), which provides a comparably comprehensive review for existing empirical studies. Although the study by Kleine et al. (2019) contributed a great deal, theoretically, to recent literature, their study meta-analyzed only two categories of antecedents of employee thriving: individual characteristics and relational resources. In addition to individual characteristics, we believe the effects of unit contextual features on thriving were also important indicators for employees' thriving at work, including those of hindrance/challenge stress, autonomy, job crafting, etc. Therefore, our study diverts the attention of following researchers from individual characteristics to a working environment when exploring the antecedents of employees' thriving at work. We also explore the relationships between the thriving of employees and the three types of agentic work behaviors in our meta-analysis as these behaviors are regarded as an important engine of thriving in the model of Spreitzer et al. (2005).

Secondly, this research includes a greater number of indicators in each category of antecedents of employee thriving in the model described by Kleine et al. (2019) and tries its best to depict a full picture of the indicators, which may lead to employees' thriving at work. In terms of relational resources, Kleine et al. (2019) metaanalyzed the relationships of employees' thriving and 10 types of relational resources: heedful relating, supportive colleague behavior, workplace civility, etc. This study adds a systemic classification to these relational resources by incorporating the model of Spreitzer et al. (2005), and assigning them to leadership, positive meaning, and work experience. Such classifications ensure a better understanding for future researchers when they attempt to interpret the corresponding resources that may lead to employees' thriving at work. Specifically, the relational resources of leadership include abusive supervision, authentic leadership, empowering leadership, LMX, servant leadership, and transformational leadership, which supplement the study of Kleine et al. (2019) with a more comprehensive analysis of the effects of various types of leadership on thriving. Additionally, a meta-analysis of the influence of positive meaning and knowledge resources (i.e., work experience) on thriving was performed, and the results demonstrate small-to-moderate positive effects.

However, with regard to personality traits, this study supplements the study of Kleine et al. (2019) of the antecedents of thriving, which included the individual characteristics of psychological capital, core self-evaluation, proactive personality, positive affectivity, negative affectivity, perceived stress, and job engagement. This study includes a meta-analysis of four types of personality traits: self-efficacy, optimism, openness, and conscientiousness. In a slight contrast to our expectations, openness does not influence thriving, whereas other types of personality traits moderately and positively influence thriving.

Thirdly, we examine the cultural differences of individualism in the relationship between antecedents and thriving at different levels of individualism. Knowledge of the influence of antecedents in different cultural contexts may assist in establishing boundary conditions for the theory of thriving. Our results are thought provoking as we find the difference of the moderating effects of individualistic culture on the relationships between employees' thriving and variables such as autonomy, feedback, supportive climate, comparing with that between thriving and variables such as organizational justice and transformational leadership. We also encourage future research to design a very finely grained empirical study to verify the different influences of culture on the relationship between thriving at work and its different correlates.

Practically, for organization managers, this study has critical implications. Firstly, it is important that managers show a concern toward the influence of unit contextual features on employee thriving. Our results indicate that work practices and scheduled procedures, such as work autonomy, work control, job crafting, and feedback, can facilitate employee thriving by prompting managers to redesign work scopes for strengthening the employee direction, thereby increasing employee learning and vitality. Additionally, cultivating an atmosphere of respect and trust is important for thriving as our results show that trust, organizational justice, and supportive climate have significant impacts on employees. These antecedents are significant factors in cultivating a trusting and respectful climate, and can contribute to the active learning and vitality in the workplace of employees.

Secondly, another managerial implication comes from the importance of leadership. Our results show that negative leadership, such as abusive supervision, negatively influences thriving. Further, various types of positive leadership, such as authentic leadership and servant leadership, significantly and positively influence thriving. Managers should acknowledge that more employees self-actualize through the social development of modern society, and, therefore, the role of supervisors will become more quiescent by providing support and authority to employees. Autocratic leadership, including abusive leadership, is not conducive to employee growth and hinders organizational development.

Finally, although there are studies that emphasize personality traits as inherent and immutable throughout the growth of an individual, our results show that, in fact, the personality traits of self-efficacy, optimism, and conscientiousness positively influence thriving. Managers frequently use personality tests for prospective employees as positive personality traits engender thriving at work. Employees with positive personality traits actively learn and have increased vitality, leading to selfdevelopment at work. 


\section{LIMITATIONS AND FUTURE DIRECTIONS}

This study has some limitations. Firstly, most of the empirical studies used in our analysis examined the antecedents of thriving at an individual level. However, fewer studies examined the high-level indicators on thriving such as group climate, inter-group communication, or intra-group communication. Furthermore, there are a limited number of studies on the influence of culture at an organizational or a national level. Therefore, we suggest that future research pays attention to the effects of high-level indicators, such as climate and culture, on employee thriving in multilevel models.

Secondly, there are a limited number of studies, which use the data from multiple sources or multiple waves. Therefore, it is not possible to analyze the moderating effects of the methodology such as the moderation of multiple raters (Zhang and Bednall, 2016). Therefore, a lot of research on thriving set one employee as a single rater. We encourage future research to employ multiple raters by using employee and colleague ratings to examine the effects of antecedents on the collective thriving of employees as individuals and relative to others. Additionally, the samples reported in most empirical studies are crosssectional, meaning that measurement and acquiescence bias were unavoidable, thus these studies may be affected by a common method bias. Therefore, we encourage future research to collect the data from multiple waves or have used experience sampling methods to test the dynamic relationship between the different levels of antecedents and employee thriving.

Finally, in this study, existing empirical studies failed to provide a full picture of the antecedents of thriving as we could not access sufficient effect sizes to metaanalyze certain antecedent-thriving relationships. For example, we intended to meta-analyze the effects of all Big-Five personality domains on thriving, but were unable to collect sufficient effect sizes for the variables of extroversion and agreeableness. Therefore, to complete the research on the antecedents of thriving at work, we encourage future research to explore further systematic indicators of thriving.

\section{REFERENCES}

Abid, G., Zahra, I., and Ahmed, A. (2015). Mediated mechanism of thriving at work between perceived organization support, innovative work behavior and turnover intention. Pak. J. Commerce Soc. Sci. 9, 982-998.

Abid, G., Zahra, I., and Ahmed, A. (2016). Promoting thriving at work and waning turnover intention: a relational perspective. Future Bus. J. 2, 127-137. doi: 10.1016/j.fbj.2016.08.001

Albi, A., Ning, W., and Wu, B. (2020). Proactive personality and creative behavior: examining the role of thriving at work and high-involvement HR practices. J. Bus. Psychol. (in press). doi: 10.1007/s10869-020-09704-5

Ali, M., Lei, S., Jie, Z. S., and Rahman, M. A. (2018). Empowering leadership and employee performance. Int. J. Asian Bus. Information Manag. 9, 1-14. doi: 10.4018/IJABIM.2018040101

\section{CONCLUSION}

Using the socially embedded model of thriving of Spreitzer et al. (2005) and the research of Kleine et al. (2019) as starting points, we systematically and comprehensively metaanalyze the relationship between antecedents and thriving at work. Our findings suggest that there are correlations between thriving at work and its antecedents, including unit contextual features, the resources produced at work, agentic work behaviors, and personality traits. Furthermore, it is shown that cultural differences, such as individualism, play a moderate role in the influence of certain antecedents on thriving at work. This study adds substantially to our understanding of which and how antecedent variables impact thriving at work. Moreover, it makes several noteworthy contributions to the influence of individualistic culture, which acts an addition to the effects of the antecedents of thriving.

\section{DATA AVAILABILITY STATEMENT}

The raw data supporting the conclusions of this article will be made available by the authors, without undue reservation.

\section{AUTHOR CONTRIBUTIONS}

DL reviewed the literature, proposed the research model, and designed the study. YY conducted the literature search, proceeded with the data extraction process, and involved in the development of the manuscript. YW conducted the statistical analysis and revised the manuscript critically for important content. DL and SZ wrote the first draft of the manuscript. All authors have approved the final manuscript to be published.

\section{FUNDING}

This work was supported by the Innovation Fund of Research Institute of International Economics and Management, Xihua University (Grant No. 20210016), and the National Natural Science Foundation of China (Grant No. 72001186).

An, J. (2015). The Mechanism Research of Authenticity Leadership Behavior and its Effect on Empoyees' Thriving at Work. China: Huaqiao University.

Atwater, L., and Carmeli, A. (2009). Leader-member exchange, feelings of energy, and involvement in creative work. Leadersh. Q. 20, 264-275. doi: 10.1016/j. leaqua.2007.07.009

Begg, C. B., and Mazumdar, M. (1994). Operating characteristics of a rank correlation test for publication bias. Biometrics 50, 1088-1101. doi: 10.2307/ 2533446

Bensemmane, S., Ohana, M., and Stinglhamber, F. (2018). Team justice and thriving: a dynamic approach. J. Managerial Psychol. 33, 229-242. doi: 10.1108/ jmp-07-2017-0223

Borenstein, M., Hedges, L., Higgins, J., and Rothstein, H. (2009). An Introduction to Meta-Analysis. Introduction to Meta-Analysis. Hoboken, NJ: John Wiley \& Sons. doi: $10.1002 / 9780470743386$ 
Brown, J. S., and Duguid, P. (1991). Organizational learning and communities-ofpractice: toward a unified view of working, learning, and innovation. Organ. Sci. 2, 40-57. doi: $10.1287 /$ orsc.2.1.40

Brown, K. W., and Ryan, R. M. (2003). The benefits of being present: the role of mindfulness in psychological well-being. J. Pers. Soc. Psychol. 84, 822-848. doi: 10.1037/0022-3514.84.4.822

Brown, S. P., Westbrook, R. A., and Challagalla, G. (2005). Good cope, bad cope: adaptive and maladaptive coping strategies following a critical negative work event. J. Appl. Psychol. 90, 792-798. doi: 10.1037/0021-9010.90. 4.792

Button, S., Mathieu, J., and Zajac, D. (1996). Goal orientation in organizational research: a conceptual and empirical foundation. Organ. Behav. Hum. Decis. Process. 67, 26-48. doi: 10.1006/obhd.1996.0063

Carmeli, A., and Spreitzer, G. M. (2009). Trust, connectivity, and thriving: implications for innovative behaviors at work. J. Creat. Behav. 43, 169-191. doi: 10.1002/j.2162-6057.2009.tb01313.x

Carmeli, A., Ben-Hador, B., Waldman, D. A., and Rupp, D. E. (2009). How leaders cultivate social capital and nurture employee vigor: implications for job performance. J. Appl. Psychol. 94, 1553-1561. doi: 10.1037/a0016429

Chen, H., Li, L., Liu, J., Wu, L., and Ji, C. (2016). Empirical research on the relationship between workplace friendship and flourish at work. J. East China Normal Univer. 5, 150-160.

Cheng, T., Mauno, S., and Lee, C. (2013). Do job control, support, and optimism help job insecure employees? a three-wave study of buffering effects on job satisfaction, vigor and work-family enrichment. Soc. Indic. Res. 118, 1269-1291. doi: 10.1007/s11205-013-0467-8

Choi, D., Oh, I. S., and Colbert, A. E. (2015). Understanding organisational commitment: a meta-analytic examination of the roles of the five-factor model of personality and culture. J. Appl. Psychol. 100, 1542-1567. doi: 10.1037/ apl0000014

Collins, L. A. (2014). Thriving at Work: Contexual Versus Non-Contexual Factors. Canada: Saint Mary's University.

Colquitt, J. A., Conlon, D. E., Wesson, M. J., Porter, C., and Ng, K. Y. (2001). Justice at the millennium: a meta-analytic review of 25 years of organizational justice research. J. Appl. Psychol. 86, 425-445. doi: 10.1037//0021-9010.86.3.425

Commer, P. J., Sci, S., Raza, B., Ali, M., Mou, and Ee, D. A. (2017). Impact of managerial coaching on employee performance and organizational citizenship behavior: intervening role of thriving at work. Pak. J. Commerce Soc. Sci. 11, 790-813.

Costa, P. T., McCrae, R. R., and Dye, D. A. (1991). Facet scales for agreeableness and conscientiousness: a revision of the NEO personality Inventory. Pers. Individ. Differ. 12, 887-898. doi: 10.1016/0191-8869(91)90177-d

Deng, J. (2016). The Mediating Role of Thriving at Work Between Organizational Justice And Organizational Citizenship Behavior. China: Guangxi University.

Dollard, M. F., Osborne, K., and Manning, I. (2013). Organization-environment adaptation: a macro-level shift in modeling work distress and morale. J. Organ. Behav. 34, 629-647. doi: 10.1002/job.1821

Dong, T. (2018). A Study on the Relationship Between Leadership Style and Thriving at Work of Medical Staff in Community Health Service Center. China: Donghua University.

Ehrhardt, K., and Ragins, B. R. (2019). Relational attachment at work: a complementary fit perspective on the role of relationships in organizational life. Acad. Manag. J. 62, 1-64. doi: 10.4324/9780429477034-1

Elliot, A. J., Chirkov, V. I., Kim, Y., and Sheldon, K. M. (2001). A cross-cultural analysis of avoidance (relative to approach) personal goals. Psychol. Sci. 12, 505-510. doi: 10.1111/1467-9280.00393

Flinchbaugh, C., Luth, M. T., and Li, P. (2015). A challenge or a hindrance? understanding the effects of stressors and thriving on life satisfaction. Int. J. Stress Manag. 22, 323-345. doi: 10.1037/a0039136

Gao, D. (2017). The Study of Impact of Perceived Organizational Support on Thriving - the Mediation Effect of Self-Efficacy. China: Guangxi University.

Gao, F. (2017). Study on the Formation Mechanism of Employee Creativity Based on Self-Determination Theory. China: China University of Mining and Technology.

Gardner, W. L., Avolio, B. J., Luthans, F., May, D. R., and Walumbwa, F. (2005). "Can you see the real me?" A self-based model of authentic leader and follower development. Leader. Q. 16, 343-372. doi: 10.1016/j.leaqua.2005. 03.003
Geiger, L. (2013). Leading Towards Well-Being Exploring Organizational Climate, Leadership and Individual Factors that Relate to Thriving at Work. California: Pepperdine University.

Ghulam, A., Iqra, S., Saman, E. N., Saira, F., Asma, N., and Jason, H. (2018). The influence of prosocial motivation and civility on work engagement: the mediating role of thriving at work. Cogent Bus. Manag. 5, 1-19. doi: 10.1080/ 23311975.2018.1493712

Ghulam, A., Saira, A., Natasha, S. E., and Sehrish, I. (2020). Antecedents and mechanism of employee well-being for social sustainability: a sequential mediation. Sustain. Prod. Consum. 24, 79-89. doi: 10.1016/j.spc.2020.06.011

Gkorezis, P., Kalampouka, P., and Petridou, E. (2013). The mediating role of belongingness in the relationship between workplace incivility and thriving. Int. J. Employment Stud. 21, 63-78.

$\mathrm{Gu}, \mathrm{Z}$. (2015). The Effect of Superior-Subordinate Guanxi on Employee's Thriving at Work. China: Shanxi University.

Han, J., and Wei, W. (2013). A review of the literature of thriving at work and prospects. Foreign Econ. Manag. 35, 46-53.

Han, L. (2017). The Impact of Empowering Leadership on Work Thriving - The Mediating Role of Job Crafting. China: Dongbei University of Finance and Economics.

Hennekam, S. (2017). Thriving of older workers. Personnel Rev. 46, 297-313. doi: 10.1108/pr-07-2015-0195

Herzberg, F., Mausner, B., and Synderman, B. (1959). The Motivation to Work. Hoboken, NJ: John Willey Publishers.

Higgins, E. T. (1997). Beyond pleasure and pain. Am. Psychol. 52, 1280-1300. doi: $10.1037 / 0003-066 x .52 .12 .1280$

Hildenbrand, K., Sacramento, C. A., and Binnewies, C. (2018). Transformational leadership and burnout: the role of thriving and followers' openness to experience. J. Occup. Health Psychol. 23, 31-43. doi: 10.1037/ocp0000051

Hofstede, G. (1984). Culture's Consequences: International Differences in WorkRelated Values. Beverly Hills, CA: Sage.

Hofstede, G. (2001). Culture's Consequences: Comparing Values, Behaviors, Institutions, and Organizations Across Nations, 2nd Edn. California: Sage Publications.

Huang, H. (2017). The Effect of Transformational Leadership on Thriving at Work: Test of a Moderated Mediator Model. China: Huaqiao University.

Hunter, J. E., and Schmidt, F. L. (2004). Methods of Meta-Analysis: Correcting Error and Bias in Research Findings, 2nd Edn. Thousand Oaks, CA: Sage. doi: $10.4135 / 9781412985031$

Jaiswal, N. K., and Dhar, R. L. (2017). The influence of servant leadership, trust in leader and thriving on employee creativity. Leadersh. Organ. Dev. J. 38, 2-21. doi: 10.1108/lodj-02-2015-0017

Jiang, Z. (2017). Proactive personality and career adaptability: the role of thriving at work. J. Vocat. Behav. 98, 85-97. doi: 10.1016/j.jvb.2016.10.003

Jiang, Z., Hu, X., Wang, Z., and Jiang, X. (2019). Knowledge hiding as a barrier to thriving: the mediating role of psychological safety and moderating role of organizational cynicism. J. Organ. Behav. 40, 800-818. doi: 10.1002/job. 2358

Kabat-Farr, D., and Cortina, L. M. (2017). Receipt of interpersonal citizenship: fostering agentic emotion, cognition, and action in organizations. J. Appl. Soc. Psychol. 47, 74-89. doi: 10.1111/jasp.12421

Kark, R., and Carmeli, A. (2010). Alive and creating: the mediating role of vitality and aliveness in the relationship between psychological safety and creative work involvement. J. Organ. Behav. 30, 785-804. doi: 10.1002/job.571

Kleine, A.-K., Rudolph, C. W., and Zacher, H. (2019). Thriving at work: a metaanalysis. J. Organ. Behav. 40, 973-999. doi: 10.1002/job.2375

Koçak, ÖE. (2016). How to enable thriving at work through organizational trust. Int. J. Res. Bus. Soc. Sci. 5, 40-52. doi: 10.20525/ijrbs.v5i4.580

Krippendorff, K. (2013). Content Analysis: An Introduction to Its Methodology. Thousand Oaks, CA: Sage Publications.

Lee, A., Aaker, J., and Gardner, W. (2000). The pleasures and pains of distinct selfconstruals: the role of interdependence in regulatory focus. J. Pers. Soc. Psychol. 78, 1122-1134. doi: 10.1037/0022-3514.78.6.1122

Lee, C.-H., Rhee, S.-Y., and Shin, I. (2015). The effect of team feedback environment on thriving at work and team commitment through feedbackseeking behavior. J. Korea Acad. Industrial Cooperation Soc. 16, 3220-3229. doi: 10.5762/kais.2015.16.5.3220 
LePine, J. A., LePine, M. A., and Jackson, C. L. (2004). Challenge and hindrance stress: relationships with exhaustion, motivation to learn, and learning performance. J. Appl. Psychol. 89, 883-891. doi: 10.1037/0021-9010.89. 5.883

Levy, R. (2016). The Role of Implicit Person Theories and Psychological Capital in Workplace Thriving. South Africa: University of Witwatersand.

$\mathrm{Li}, \mathrm{J}$. (2015). The mediating roles of job crafting and thriving in the LMX-employee outcomes relationship. Japn. J. Adm. Sci. 28, 39-51. doi: 10.5651/jaas.28.39

Li, J. (2018). Research on the Function Mechanism of Guanxi Governance and Working Relationship to Thriving at Work. China: Jiangxi University of Finance and Economics.

Li, M., Liu, W., Han, Y., and Zhang, P. (2016). Linking empowering leadership and change-oriented organizational citizenship behavior: the role of thriving at work and autonomy orientation. J. Organ. Change Manag. 29, 732-750. doi: 10.1108/jocm-02-2015-0032

Liu, C., Spector, P. E., and Shi, L. (2007). Cross-national job stress: a quantitative and qualitative study. J. Organ. Behav. 28, 209-239. doi: 10.1002/job.435

Liu, D., Jiang, K., Shalley, C. E., Keem, S., and Zhou, J. (2016). Motivational mechanisms of employee creativity: a meta-analytic examination and theoretical extension of the creativity literature. Organ. Behav. Hum. Decis. Process. 137, 236-263. doi: 10.1016/j.obhdp.2016.08.001

Liu, H. (2017). The Impact Mechanism of High Performance Work System on Thriving at Work. China: Jiangnan University.

Liu, J., and Bern-Klug, M. (2013). Nursing home social services directors who report thriving at work. J. Gerontol. Soc. Work 56, 127-145. doi: 10.1080/ 01634372.2012 .750255

Liu, Y. (2016). Research on the Relationship Between Thriving at Work and the Voice Behavior: Take Abusive Supervision as a Moderator Variable. China: Dongbei University of Finance and Economics.

Liu, Y., Xu, S., and Zhang, B. (2019). Thriving at work: how a paradox mindset influences innovative work behavior. J. Appl. Behav. Sci. 56, 347-366. doi: $10.1177 / 0021886319888267$

Luo, F. (2016). The Effect of Customer Aggressive Mistreatment on Turnover Intention: Roles of Thriving at Working and Servant Leadership. China: Harbin Institute of Technology.

Luthans, F., Avolio, B. J., Avey, J. B., and Norman, S. M. (2007). Positive psychological capital: measurement and relationship with performance and satisfaction. Pers. Psychol. 60, 541-572. doi: 10.1111/j.1744-6570.2007.00083.x

Maurer, T. J., Mitchell, D. R. D., and Barbeite, F. G. (2002). Predictors of attitudes toward a 360-degree feedback system and involvement in postfeedback management development activity. J. Occup. Organ. Psychol. 75, 87-107. doi: $10.1348 / 096317902167667$

Moreland, R. L., and Argote, L. (2003). "Transactive memory in dynamic organizations," in Understanding the Dynamic Organization, eds R. Peterson and E. A. Mannix (Mahwah, NJ: Erlbaum), 135-162.

Mortier, A., Vlerick, P. V., and Clays, E. (2016). Authentic leadership and thriving among nurses: the mediating role of empathy. J. Nursing Manag. 24, 357-365. doi: 10.1111 /jonm. 12329

Mukhaimer, R. (2012). The Relations Between Initial Training with Autonomous Motivation, Thriving and Turnover Intentions of Recruiters in the Staffing Industry. Canada: Concordia University.

Mushtaq, M., Abid, G., Sarwar, K., and Ahmed, S. (2017). Forging ahead how to thrive at the modern workplace. Iran. J. Manag. Stud. 10, 783-818.

$\mathrm{Na}$, X. J. (2017). Study on the Influence of Work-Family Enrichment on Work Thriving-Based on the Mediator of Psychological Capital. China: Northeastern University of Finance and Economics.

Niessen, C., Mäder, I., Stride, C., and Jimmieson, N. L. (2017). Thriving when exhausted: the role of perceived transformational leadership. J. Vocat. Behav. 103, 41-51. doi: 10.1016/j.jvb.2017.07.012

Niessen, C., Sonnentag, S., and Sach, F. (2012). Thriving at work-a diary study. J. Organ. Behav. 33, 468-487. doi: 10.1002/job.763

Novaes, V. P., Ferreira, M. C., Mendonça, H., and Torres, C. V. (2020). Antecedents and consequents of prosperity at work: a mediation-moderation model. Revista de administração mackenzie 21, 1-28. doi: 10.1002/9781118901731.iecrm 0038

Panagiotis, G., Panagiota, K., and Eugenia, P. (2013). The mediating role of belongingness in the relationship between workplace incivility and thriving. Int. J. Employment Stud. 21, 63-78.
Parkes, L. P., Bochner, S., and Schneider, S. K. (2001). Person -organisation fit across cultures: an empirical investigation of individualism and collectivism. Appl. Psychol. Int. Rev. 50, 81-108. doi: 10.1111/1464-0597.00049

Paterson, T. A., Luthans, F., and Jeung, W. (2014). Thriving at work: impact of psychological capital and supervisor support. J. Organ. Behav. 35, 434-446. doi: $10.1002 /$ job. 1907

Pfeffer, J. (2010). Building sustainable organizations: the human factor. Acad. Manag. Perspect. 24, 34-45. doi: 10.5465/amp.2010.50304415

Porath, C., Spreitzer, G., Gibson, C., and Garnett, F. G. (2012). Thriving at work: toward its measurement, construct validation, and theoretical refinement. J. Organ. Behav. 33, 250-275. doi: 10.1002/job.756

Prem, R., Ohly, S., Kubicek, B., and Korunka, C. (2017). Thriving on challenge stressors? exploring time pressure and learning demands as antecedents of thriving at work. J. Organ. Behav. 38, 108-123. doi: 10.1002/job.2115

Quick, J. C., Nelson, D. L., and Quick, J. D. (1990). Stress and Challenge at the Top: the Paradox of the Successful Executive. Hoboken, NJ: Wiley.

Rattrie, L., Kittler, M. G., and Paul, K. I. (2020). Culture, burnout and engagement: a meta-analysis on national cultural values as moderators in JD-R theory. Psychology 69, 176-220. doi: 10.1111/apps.12209

Raza, B., and Ahmed, A. (2020). Linking managerial coaching and workplace deviance: the mediating role of thriving at work. Iran. J. Manag. Stud. 13, 467-494.

Ren, H., Yunlu, D. U., Shaffer, M., and Fodchuk, K. M. (2015). Expatriate success and thriving: the influence of job deprivation and emotional stability. J. World Bus. 50, 69-78. doi: 10.1016/j.jwb.2014.01.007

Rhoades, L., and Eisenberger, R. (2002). Perceived organizational support: a review of the literature. J. Appl. Psychol. 87, 698-714. doi: 10.1037/0021-9010.87.4.698

Ronen, S., and Mikulincer, M. (2009). Attachment orientations and job burnout: the mediating roles of team cohesion and organisational fairness. J. Soc. Pers. Relationsh. 26, 549-567. doi: 10.1177/0265407509347930

Rosenthal, R. (1979). The file drawer problem and tolerance for null results. Psychol. Bull. 86, 638-641. doi: 10.1037/0033-2909.86.3.638

Rozkwitalska, M. (2018). Thriving in mono- and multicultural organizational contexts. Int. J. Contemp. Manag. 17, 233-247. doi: 10.4467/24498939IJCM. 18.013.8392

Russo, M., Buonocore, F., Carmeli, A., and Guo, L. (2018). When family supportive supervisors meet employees' need for caring: implications for workfamily enrichment and thriving. J. Manag. 44, 1678-1702. doi: 10.1177/ 0149206315618013

Ryan, R. M., and Deci, E. L. (2000). Self-determination theory and the facilitation of intrinsic motivation, social development, and well-being. Amer. Psychol. 55, 68-78. doi: 10.1037/0003-066x.55.1.68

Shen, L., Zhang, R., and Yu, L. (2018). The effects of authentic leadership on employee's thriving at work-— the mediating role of psycholgical capital. Soft Sci. 32, 90-94.

Sia, S. K., and Duari, P. (2018). Agentic work behaviour and thriving at work: role of decision making authority. Benchmarking Int. J. 25, 3225-3237. doi: 10.1108/bij-07-2017-0204

Spector, B., Allen, T. D., Poelmans, S., Lapierre, L., Cooper, C. L., O’Driscoll, M., et al. (2007). Cross-national differences in relationships of work demands, job satisfaction, and turnover intentions with work-family conflict. Pers. Psychol. 60, 805-835. doi: 10.1111/j.1744-6570.2007.00092.x

Spreitzer, G., Porath, C. L., and Gibson, C. B. (2012). Toward human sustainability: how to enable more thriving at work. Organ. Dyn. 41, 155-162. doi: 10.1016/j. orgdyn.2012.01.009

Spreitzer, G., Sutcliff, K., Dutton, J., Sonenshein, S., and Grant, A. M. (2005). A socially embedded model of thriving at work. Organ. Sci. 16, 537-549. doi: $10.1287 /$ orsc. 1050.0153

Taras, V., Kirkman, B. L., and Steel, P. (2010). Examining the impact of culture's consequences: a three-decade, multilevel, meta-analytic review of hofstede's cultural value dimensions. J. Appl. Psychol. 95, 405-439. doi: 10.1037/a00 18938

Taras, V., Steel, P., and Kirkman, B. L. (2011). Three decades of research on national culture in the workplace: do the differences still make a difference? Organ. Dyn. 40, 189-198. doi: 10.1016/j.orgdyn.2011. 04.006

Ted, A. P., Fred, L., and Wonho, J. (2013). Thriving at work: impact of psychological capital and supervisor support. J. Organ. Behav. 35, 434-446. 
Usman, M., Liu, Y., Zhang, J., Ghani, U., and Gul, H. (2021). Why do employees struggle to thrive in the workplaces? a look at the impact of Abusive supervision. Pers. Rev. (in press). doi: 10.1108/PR-04-2019-0213

van Scheppingen, A. R., de Vroome, E. M., Ten Have, K. C., Zwetsloot, G. I., Wiezer, N., and van Mechelen, W. (2015). Vitality at work and its associations with lifestyle, self-determination, organizational culture, and with employees' performance and sustainable employability. Work 52, 45-55. doi: 10.3233/wor141947

Walumbwa, F. O., Muchiri, M. K., Misati, E., Wu, C., and Meiliani, M. (2018). Inspired to perform: a multilevel investigation of antecedents and consequences of thriving at work. J. Organ. Behav. 39, 249-261. doi: 10.1002/job.2216

Wang, R. (2018). The Effects of Job Crafting on Thriving. China: Central China Normal University.

Wang, Z., Gao, F., and Ye, X. (2017). How does supervisor developmental feedback influence individual creativity? - - a mediated moderation model. Collected Essays Finance Econ. 88-97.

Wenger, E. (1998). Communities of practice: learning, meaning and identity. J. Mathematics Teacher Educ. 6, 185-194. doi: 10.1017/CBO97805118 03932

Wrzesniewski, A., and Dutton, J. E. (2001). Crafting a job: revisioning employees as active crafters of their work. Acad. Manag. Rev. 26, 179-201. doi: 10.5465/ AMR.2001.4378011

Xie, B. (2016). The Impact of Job Characteristics on Thriving at Work from Creative Talents. China: Huaqiao University.

Xie, X. (2015). The Relationship of Work-Related Vigor, Psychological Capital and Organizational Citizenship Behavior in Teachers of Primary and Secondary School. China: Minnan Normal University.

$\mathrm{Xu}$, A. J., Loi, R., and Chow, C. (2020). Can taking charge at work help hospitality frontline employees enrich their family life? Int. J. Hospitality Manag. 89:102594. doi: 10.1016/j.ijhm.2020.102594

Xu, B. D., Zhao, S. K., Li, C. R., and Lin, C. J. (2017). Authentic leadership and employee creativity: testing the multilevel mediation model. Leadersh. Organ. Dev. J. 38, 482-498. doi: 10.1108/lodj-09-2015-0194

Xu, S., Wang, Y., Mu, R., Jin, J., and Gao, F. (2018). The effects of work-family interface on domain-specific satisfaction and well-being across nations: the moderating effects of individualistic culture and economic development. PsyCh J. 7, 248-267. doi: 10.1002/pchj.226

Yang, Y., Li, Z. Q., Liang, L., and Zhang, X. (2021). Why and when paradoxical leader behavior impact employee creativity: thriving at work and psychological safety. Curr. Psychol. 40, 1911-1922. doi: 10.1007/s12144-018-0095-1

Zhang, J., Bal, P. M., Akhtar, M. N., Long, L., Zhang, Y., and Ma, Z. (2018). Highperformance work system and employee performance: the mediating roles of social exchange and thriving and the moderating effect of employee proactive personality. Asia Pacific J. Hum. Resour. 57, 369-395. doi: 10.1111/1744-7941. 12199

Zhang, R. G., Shen, L., and Yu, L. (2018). The effect of LMX on new generation employees' thriving at work: the multiple mediating role of perceived organizational support. Modern Finance Econ. J. Tianjin Univer. Finance Econ. 39, 101-113. doi: 10.1348/096317905x39657

Zhang, W. (2018). Research on the Influencing Mechanism of Career Management and Employees' Thriving at Work. China: Capital University of Economics and Business.

Zhang, Y., and Bednall, T. C. (2016). Antecedents of abusive supervision: a meta-analytic review. J. Bus. Ethics 139, 455-471. doi: 10.1007/s10551-0152657-6

Zhang, Y., Xu, S., Jin, J., and Ford, M. T. (2017). The within and cross domain effects of work-family enrichment: a meta-analysis. J. Vocat. Behav. 104, 210 227. doi: 10.1016/j.jvb.2017.11.003

Zhang, Z., Li, P., Zhang, L., Zheng, J., and Xue, Z. (2020). Helping neighbors and enhancing yourself: a spill over effect of helping neighbors on work-family conflict and thriving at work. Curr. Psychol. doi: 10.1007/s12144-020-00864-4 Online Head of Print.

Zhao, S. H., Shi, Y., Sun, Z. N., Xie, F. Z., Wang, J. H., Zhang, S. E., et al. (2018). Impact of workplace violence against nurses' thriving at work, job satisfaction and turnover intention: a cross-sectional study. J. Clin. Nursing 27, 2620-2632. doi: 10.1111/jocn.14311

Zhu, X., Law, K. S., Sun, C. T., and Yang, D. (2019). Thriving of employees with disabilities: the roles of job self-efficacy, inclusion, and team-learning climate. Hum. Resour. Manag. 58, 21-34. doi: 10.1002/hrm.21920

Conflict of Interest: The authors declare that the research was conducted in the absence of any commercial or financial relationships that could be construed as a potential conflict of interest.

Publisher's Note: All claims expressed in this article are solely those of the authors and do not necessarily represent those of their affiliated organizations, or those of the publisher, the editors and the reviewers. Any product that may be evaluated in this article, or claim that may be made by its manufacturer, is not guaranteed or endorsed by the publisher.

Copyright (c) 2021 Liu, Zhang, Wang and Yan. This is an open-access article distributed under the terms of the Creative Commons Attribution License (CC BY). The use, distribution or reproduction in other forums is permitted, provided the original author(s) and the copyright owner(s) are credited and that the original publication in this journal is cited, in accordance with accepted academic practice. No use, distribution or reproduction is permitted which does not comply with these terms. 